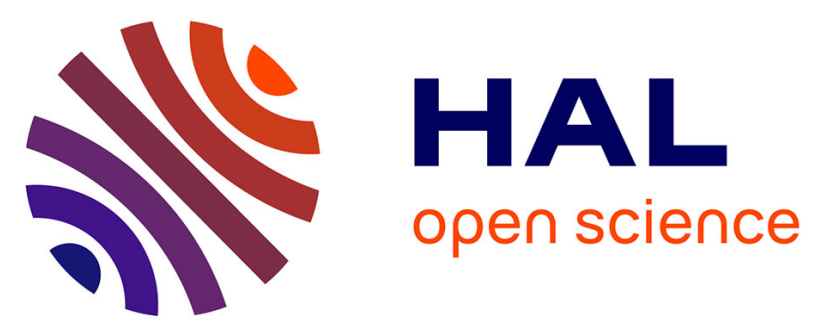

\title{
Tissue damage induces a conserved stress response that initiates quiescent muscle stem cell activation
}

\author{
Léo Machado, Perla Geara, Jordi Camps, Matthieu Dos Santos, Fatima \\ Teixeira- Clerc, Jens van Herck, Hugo Varet, Rachel Legendre, Jean-Michel \\ Pawlotsky, Maurilio Sampaolesi, et al.
}

\section{To cite this version:}

Léo Machado, Perla Geara, Jordi Camps, Matthieu Dos Santos, Fatima Teixeira- Clerc, et al.. Tissue damage induces a conserved stress response that initiates quiescent muscle stem cell activation. Cell Stem Cell, 2021. hal-03420683

\section{HAL Id: hal-03420683 https://hal.science/hal-03420683}

Submitted on 9 Nov 2021

HAL is a multi-disciplinary open access archive for the deposit and dissemination of scientific research documents, whether they are published or not. The documents may come from teaching and research institutions in France or abroad, or from public or private research centers.
L'archive ouverte pluridisciplinaire HAL, est destinée au dépôt et à la diffusion de documents scientifiques de niveau recherche, publiés ou non, émanant des établissements d'enseignement et de recherche français ou étrangers, des laboratoires publics ou privés. 


\section{Tissue damage induces a conserved stress response that initiates quiescent muscle stem cell activation}

Léo Machado ${ }^{1, \#}$, Perla Geara ${ }^{1, \#}$, Jordi Camps ${ }^{2,3,}$, Matthieu Dos Santos ${ }^{4, \S}$, Fatima TeixeiraClerc $^{1}$, Jens Van Herck ${ }^{5}$, Hugo Varet ${ }^{6,7}$, Rachel Legendre ${ }^{6,7}$, Jean-Michel Pawlotsky ${ }^{1,8}$, Maurilio Sampaolesi ${ }^{2,9}$, Thierry Voet $^{5,10}$, Pascal Maire ${ }^{4}$, Frederic Relaix ${ }^{1,11,12,13,14, *}$, and Philippos Mourikis, ${ }^{1, *}$.

\#These authors contributed equally, §These authors contributed equally, *corresponding author

1. Univ Paris Est Creteil, INSERM, IMRB, F-94010 Creteil, France

2. Laboratory of Translational Cardiomyology, Department of Development and Regeneration, Stem Cell Research Institute, KU Leuven, 3000 Leuven, Belgium

3. Bayer AG, 13353 Berlin, Germany

4. Université d Paris, Institut Cochin, INSERM, CNRS, 75014 Paris, France

5. Laboratory of Reproductive Genomics, Department of Human Genetics, KU Leuven, 3000 Leuven, Belgium

6. Hub de Bioinformatique et Biostatistique - Département Biologie Computationnelle, Institut Pasteur, USR 3756 CNRS, 75015 Paris, France

7. Plate-forme Biomics - Centre de Ressources et Recherches Technologiques (C2RT), Institut Pasteur, 75015 Paris, France

8. Département de Virologie, Hôpital Henri Mondor, F-94010 Créteil, France

9. Human Anatomy Unit, Department of Public Health, Experimental and Forensic Medicine, University of Pavia, 27100 Pavia, Italy.

10. Wellcome Sanger Institute, Wellcome Genome Campus, Cambridge CB10 1SA, UK.

11. EnvA, IMRB, F-94700 Maisons-Alfort, France

12. EFS, IMRB, F-94010 Creteil, France

13. AP-HP, Hopital Mondor, Service d'histologie, F-94010 Creteil, France

14. Lead Contact

Lead contact: frederic.relaix@inserm.fr

Correspondence: frederic.relaix@inserm.fr (F.R.), philippos.mourikis@inserm.fr (Ph.M) 


\section{SUMMARY}

Tissue damage dramatically alters how cells interact with their microenvironment. These changes in turn dictate cellular responses, such as stem cell activation, yet early cellular responses in vivo remain ill-defined. We generated single cell and nucleus atlases from intact, dissociated, and injured muscle and liver, and identified a common stress response signature shared by multiple cell types across these organs. This prevalent stress response was detected in published datasets across a range of tissues, demonstrating high conservation but also a significant degree of data distortion in single-cell reference atlases. Using quiescent muscle stem cells as a paradigm of cell activation following injury, we captured early cell activation following muscle injury and found that an essential ERK1/2 primary proliferation signal precedes initiation of the Notch-regulated myogenic program. This study defines initial events in response to tissue perturbation and identifies a broadly-conserved transcriptional stress response that acts in parallel with cell-specific adaptive alterations. 


\section{INTRODUCTION}

Cell plasticity is a fundamental property in response to injury in a variety of vertebrate organs. Tissue damage triggers activation and proliferation of stem/progenitor cells in order to restore homeostasis, as seen in the bone, skin, and skeletal muscle amongst others (Fuchs and Blau, 2020; Jessen et al., 2015). Differentiated cells too can get activated and eventually proliferate following de-differentiation, as is the case for hepatocytes after hepatectomy (Riehle et al., 2011) or neonatal mouse cardiomyocytes (Porrello et al., 2011). Cell death pathways, however, can also be instigated when cell injury is irreversible (Rathore et al., 2017). Uncovering the early transcriptional roadmap of the cells as they exit homeostasis is critical for understanding their properties and developing tools for experimental manipulation. Despite extensive research, however, the degree, kinetics and nature of the early, cell-type specific or conserved responses to tissue damage as they occur in vivo remain poorly defined.

A major limitation in capturing the early responses in vivo is that the process of cell isolation induces major transcriptional modifications that mask the actual injury-induced changes. Early studies that uncovered the global transcriptional changes in standard cell dissociation methods were performed on quiescent skeletal muscle stem cells (MuSCs), (Brink et al., 2017; Machado et al., 2017; van Velthoven et al., 2017). Yet, it was perceived that these changes are a particular feature of quiescent stem cells, and MuSCs in particular, as they have evolved to become activated following disruptions in their niche homeostasis. Several studies, however, have reported transcriptional changes in diverse cellular systems during ex vivo cell isolation, challenging the notion that this is unique to MuSCs (Adam et al., 2017; Bakken et al., 2018; Lacar et al., 2016; O'Flanagan et al., 2019; Wu et al., 2019, 2017). Considering the evergrowing importance of transcriptional studies and reference atlases, understanding whether the changes are technical artefacts linked with cell isolation and RNA recovery methods or if they are caused by loss of niche signals is critical. Here, we have developed specialized protocols to identify the kinetics and nature of the stress response to tissue damage in diverse tissues and cell types. We identify a broadly conserved stress response across organs and cell types and uncover a functional role of this response, using MuSCs as a model of quiescent stem cell activation. 


\section{RESULTS}

Definition of a core stress signature in muscle and liver in response to cell dissociation In order to test the impact of cell dissociation across cell types and tissues, we performed singlenucleus RNA-seq (snRNA-seq) on intact or dissociated murine skeletal muscle and liver using a droplet-based platform (Fig. 1A) and identified 26,074 single-nucleus transcriptomes (Fig. S1A-D), distributed in 10 main populations in the muscle and 7 in the liver (Fig. 1B; S1E, F). When all nuclei of a tissue were merged, we noticed that cells tended to cluster by type yet there was a clear separation between intact and dissociated cells, indicating strong transcriptional differences (Fig. 1C). Remarkably, nearly all dissociated cells showed high induction of Jun, a prototypical stress-response gene (Fig. S1G), (Bohmann et al., 1987).

Differential gene expression analysis indicated variable yet strong modifications in all cell types during dissociation, with an average of 1,226 differentially expressed genes (DEGs) in the main 10 cell-types studied (Fig. S1H). Notably, for MuSCs the detected DEGs were highly similar to previous dissociation-induced differences found by bulk RNAseq (Machado et al., 2017), validating the single-nucleus approach (Fig. S1I, J). Analysis of the upregulated genes showed enrichment for cell-specific biological processes, as described in supplemental figure S1K-N. We then examined the extent to which the dissociation-induced modifications were shared between cell types. Approximately half of the up-regulated genes were cell-type specific while the rest were induced in at least two populations (Fig. 1D). A similar pattern was observed for the down-regulated genes (Fig. S2A).

Importantly, we uncovered a conserved transcriptional core composed of 98 genes that was induced in at least 7 of the 10 main cell types (Fig. 1E; S2B, supplementary Table 1). The average expression of this gene set was designated as the Stress Index and was validated in our snRNA-seq dataset (Fig. S2C). Gene ontology analysis of the stress core was enriched for terms linked to MAPK signaling, response to growth factors and cytokines, and initiation of transcription (Fig. 1F). Consistently, phospho-ERK1/2 showed rapid induction of MAPK activation at $15 \mathrm{~min}$ of muscle digestion (Fig. S2D).

Based on the broad modifications that we observed in muscle and liver cells during dissociation, we extended our analysis to a multi-organ murine single-cell atlas (Tabula Muris; Schaum et al., 2018) ), (Fig. 1G and S2E). Stress Index scored high for most cells of the muscle but only a fraction of the liver atlas (Fig. S2F), in contrast to our data on dissociated liver (Fig. S2C). 
We postulated that these variations were linked to the time of the cell-dissociation procedure. To corroborate this hypothesis, we inferred the digestion time for every cell from the Tabula Muris dataset (supplementary Table 2) and found a strong correlation between dissociation time and Stress Index (Fig. 1G, H; S2G, H). This correlation held across organs, with those dissociated for more than $60 \mathrm{~min}$ - such as the bladder, the tongue, the trachea, the limb muscle or the mammary gland - presenting with a high Stress Index, while tissues dissociated for less than $20 \mathrm{~min}$ - such as the liver, the marrow, the spleen, the pancreas or the brain presenting with a low Stress Index (Fig. S2I, J). In order to test for bias due to cell type composition, we calculated the median Stress Index per cell type across all tissues and, consistently, observed the same positive correlation with median dissociation time (Fig. 1I; $\mathrm{S} 2 \mathrm{~K})$.

\section{Analysis of the cellular response to in vivo tissue injury}

The gene expression modifications that we found were identified in cells during experimental cell dissociation. However, it remained unknown what is the early transcriptional response to tissue damage in vivo. To address this, we performed single-nucleus transcriptomic analysis shortly after a chemically-induced injury of the liver and the skeletal muscle (Fig. 2A). Following a screening for the stress-response kinetics (Fig. S3A), we generated a snRNA-seq atlas from injured livers $4 \mathrm{~h}$ post carbon tetrachloride $\left(\mathrm{CCl}_{4}\right)$ injection (Teixeira-Clerc et al., 2010) and compared it to uninjured liver (Fig. 2B; S3B-D). Strong transcriptional changes were detected in all identified populations, as shown by the clear separation of the uninjured from the injured clusters (Fig. 2C) with a high Stress Index detected specifically in the injured-liver derived hepatocytes (Fig. 2D). We also performed injury of the Tibialis Anterior (TA) hindlimb muscle by intramuscular injection of barium chloride $\left(\mathrm{BaCl}_{2}\right)$ (Casar et al., 2004). We first determined the stress response kinetics (Fig. S3E) and generated snRNA-seq atlases from muscles collected $4 \mathrm{~h}$ post $\mathrm{BaCl}_{2}$-injection (Fig. 2B; S3C, F, G). Analysis showed that the activated populations clustered separately from their corresponding populations in intact muscles (Fig. 2C) and a high Stress Index (Fig. 2D).

To expand our analysis on the kinetics of a specialized stem cell population in vivo, we performed single-cell RNA-seq (scRNA-seq) on MuSCs at different time-points post-injury, by adapting the SMARTseq2 scRNA-seq for in Situ Fixation (iSiFi) treated samples. MuSCs were FACS-isolated at $2 \mathrm{~h}$ and $4 \mathrm{~h}$ post $\mathrm{BaCl}_{2}$ injury (T2 and $\mathrm{T} 4$ ) and compared to uninjured muscle (T0), (Fig. 2E). Following quality controls, we analyzed $280 \mathrm{MuSCs}$ (Fig. S4A-F). Principal components analysis (PCA) grouped the cells according to their experimental 
condition and showed transcriptional consistency within clusters yet marked differences between time-points (Fig. 2F). Of note, quiescent T0-MuSCs formed a unique, compact cluster indicating a relatively homogeneous cell population, whereas the activated cells appeared more scattered while remaining distinct (Fig. 2F; S4G).

To precisely order cells along the activation path, we performed pseudotime analysis (Street et al., 2018) and observed a continuous trajectory, suggesting that all cells transitioned evenly from T0 to T2 to T4 state but with variable kinetics (Fig. 2G). Furthermore, to crosscorrelate in vivo activation and the stress response core genes, we visualized the Stress Index of each cell according to its pseudotime value. We noticed that MuSCs activated in vivo exhibited a strong and transient induction of the Stress-core genes (Fig. 2H), indicating that the transcription of the early response genes is transient and dynamic. Finally, implementation of the $i S i F i$ protocol during early activation, enabled us to provide an explanation for some puzzling features in high-quality single-cell datasets on quiescent MuSCs (Camps et al., 2020; Dell'Orso et al., 2019; Giordani et al., 2019; Schaum et al., 2018); namely, the low detection of the MuSCs hallmark gene $\operatorname{Pax} 7$ and, paradoxically, the high abundance of several oncogene transcripts, such as Egrl, Jun, and Fos (Fig. S4H-J), which have been shown to be expressed in activated MuSCs (Wang et al., 2018).

\section{Time-course analysis of MuSCs quiescence exit reveals modules of co-regulated genes.}

To further define the kinetics of MuSCs quiescence-exit, we generated a comprehensive timecourse transcriptional map on $i S i F i$-processed muscle stem cells. In situ fixed MuSCs were isolated by FACS every 30 min for $2 \mathrm{~h}$ during the standard dissociation procedure and RNAsequenced in bulk. A time-point of $15 \mathrm{~min}$ (T15) was introduced to detect earlier transcriptional events (Fig. 3A). PCA on the transcriptomes clustered samples by timepoints and formed a clear activation trajectory along the three main principal components (Fig. 3B). Following 15 min, 42 genes were upregulated $(\mathrm{FC}>2, \mathrm{p}<0.05)$ and most differential expression events took place at T60, reaching a maximum at T120 $(>3,000$ DEGs, FC $>2$; Fig. 3C). The identity of the DEGs at T120 was highly similar to our previous report (Machado et al., 2017), (S4K).

Using hierarchical clustering, transcripts with related kinetics were grouped in 5 clusters (Fig. 3D-F). Cluster 1 contained 36 out of the 42 upregulated genes following $15 \mathrm{~min}$ of dissociation, including immediate and early response genes (Ier2, Ier3, Egrl, and Egr2) and members of the AP-1 family of oncogenes and ERK1/2 targets (Jun, Junb, Jund, Fos and Fosb). Of note, cluster 
1 pattern of expression was characterized by a peak at T60 that rapidly reverted close to T0levels after $2 \mathrm{~h}$ of digestion (Fig. 3F), a stereotypical expression pattern of growth-factor or stress driven responses (Barton et al., 1996).

Transcriptional events directly linked to the myogenic program were found well into the second hour of digestion, such as the induction of Myod (cluster 3, 11.9 upregulated in T120 compared to T0) or the downregulation of the MuSCs quiescence markers Pax7 (Seale et al., 2000), Spryl (Chakkalakal et al., 2012), and Calcr (Yamaguchi et al., 2015), (cluster 4, foldchanges of 3.5, 3.2 and 1.7 respectively in T0 / T120). Similarly, we scored attenuation of Notch signaling at the latest time-points, with pathway canonical target genes Heyl, Hesl and HeyL being downregulated at T60, T90 and T120, respectively, compared to T0. Counterintuitively, but consistent with its role as an adaptor protein of kinase complexes, the cell cycle inhibitor encoding gene Cdknla (p21) was up-regulated by the dissociation procedure (cluster 2, fold-change of 29.9 in T120/T0). By ontology analysis we propose that the 5 clusters did not differ merely on the gene expression patterns but also exhibited distinct functional identities (Fig. S4L).

To investigate the similarities in MuSCs activation between in vivo muscle injury and ex vivo muscle dissociation, we integrated the scRNA-seq from the injured TA with the bulk RNA-seq time-course (Fig. 2E and 3A, respectively). First, we projected the dissociated MuSCs onto the PCA-space of in vivo activated MuSCs. PC1 and PC2 accurately positioned the ex vivo dissociated samples according to their digestion time, from T0 to T120 (Fig. 3G). Next, we investigated the behavior of the 5 genetic clusters identified ex vivo into the injury-activated MuSC and found a striking similarity in the dynamic behavior of genes across all clusters (Fig. $3 \mathrm{H})$. Finally, we confirmed statistically this observation using an analysis of covariance (ANCOVA) and found no significant differences in the genetic behavior of 4 out of the 5 clusters investigated (Fig. S4M). Of note, Cluster 1 genes differed between experimental models possibly due to the highly dynamic nature of genes in this cluster.

\section{Functional role of early response to MuSCs activation.}

Having established that a broadly conserved stress response occurs with cell activation, we investigated its functional role on muscle stem cell activity. As part of the early stress response, we identified Odcl and Azinl (Fig. 1E and 3E), whose products form a complex for the synthesis of the polyamine spermidine that is important in cell proliferation, growth, translation 
initiation and elongation (Mandal et al., 2013). In turn, spermidine is the source of the amino acid hypusine, a unique post-translational addition to the eukaryotic translation initiation factor eIF5A (Schuller et al., 2017), that was also found to be transcriptionally induced during activation. To test the role of polyamine biosynthesis on the $\mathrm{G}_{0}$-to-S transition of quiescent cells, we cultured freshly isolated MuSCs with the ODC1 inhibitor $d, 1-\alpha-$ difluoromethylornithine (DFMO) for $40 \mathrm{~h}$ and quantified EdU incorporation. DFMO treatment resulted in significantly decelerated cell-cycle entry. Interestingly, decreased proliferation did not lead to accelerated differentiation but instead DFMO treatment retained a more upstream PAX7+/Myogenin- cell population, compared to control (Fig. 4A, B).

We then focused on two major signaling pathways, MAPK and Notch, that showed opposite yet potent responses to tissue damage. MAPK was strongly and immediately induced whereas Notch was gradually downregulated as MuSCs entered the myogenic program (Fig. 3E for Hes1, Heyl, and HeyL; S4D for ERK1/2 phosphorylation). To test the significance of these pathways and their potential interaction during early MuSC activation, we generated mice conditionally overexpressing a constitutively active form of Notch1 (NICD) in MuSCs (Pax7 $7^{\text {CreERT2 }}$; Rosa $a^{\text {stop-NICD }}$ ) and cultured muscle cells with or without the ERK1/2 inhibitor SCH772984 (Fig. 4C). NICD impeded the expression of the activation marker MYOD and, probably as a consequence, delayed entry to the S-phase (Mourikis and Tajbakhsh, 2014), (Fig. 4C). Treatment with SCH772984 did not impact the antagonistic effect of NICD on MYOD but strongly blocked cell cycle entry (Fig. 4C). After 3 days in culture, the majority of control NICD cells cycled and all were positive for PAX7 (Fig. 4D). Of interest, the combination of ERK inhibition and Notch activation maintained MuSCs in a quiescent-like state for at least $72 \mathrm{~h}$ in culture (EdU-, Pax7+, Myog-) with spindle-shaped nuclei, characteristic of quiescent MuSCs (Machado et al., 2017), (Fig. 4D). Taken together, our data suggest that Notch and ERK pathways are partially uncoupled, whereby an early ERK signal is the driving force of MuSCs proliferation and Notch downregulation is priming the progression into the myogenic differentiation program. Next, to test directly the significance of the early stress response to stem cell activation, ERK signaling was blocked during the $2 \mathrm{~h}$ of the dissociation process and then MuSCs were plated in proliferation medium (Fig. 4E; S4N, O). Remarkably, this treatment significantly impaired the capacity of these cells to enter S-phase, providing strong evidence for the importance of the early stress response on MuSCs quiescence exit (Fig. 4F; S4P). 


\section{Discussion}

In this study, we have captured the primary cellular responses to niche damage, focusing on two highly regenerative tissues, the skeletal muscle and the liver. By analyzing a large number of diverse cells, we defined a conserved transcriptional response to tissue damage that appears to depend primarily on the duration of the stressors' signal rather than the cell type. Since different cells are serving diverse functions during regeneration, the core stress response is also likely to operate in a variety of specialized functions. Indeed, in the muscle, quiescent MuSCs and FAPs enter a proliferation phase in response to injury, whereas terminally differentiated myonuclei are wasted and replaced, yet still manifest the stress core response. Moreover, the nature of the stress that cells encounter leading to this response remains unclear. Tissue damage involves cell lysis and release of growth factors and cytokines, mechanical changes such as loss of adhesion and physical barriers and loss of cell contact with ligand-bearing cells to name a few. With such a complexity of damage-induced processes, it is likely that the trigger of the stress response is multifactorial. Our results that ERK1/2 inhibition is mitigating the activation of MuSC points towards growth factors playing a prominent role in this process.

Using specialized protocols, we have generated single-cell atlases that accurately capture the transcriptional states of cells as they exist in the context of their native tissue. Recent studies have reported that dissociation impacts the transcriptome of freshly-isolated neurons (Bakken et al., 2018; Lacar et al., 2016; Wu et al., 2017), kidney cells (Adam et al., 2017; Wu et al., 2019), and MuSCs (Brink et al., 2017; Machado et al., 2017; van Velthoven et al., 2017). Methods including iSiFi (Machado et al., 2017; van Velthoven et al., 2017), single-nucleus RNA-seq (Bakken et al., 2018; Lacar et al., 2016; Dos Santos et al., 2020; Wu et al., 2019), cold dissociation (Adam et al., 2017) and spatial transcriptomics (Eng et al., 2019; Rodriques et al., 2019; Wang et al., 2018) will represent an array of invaluable tools that can be utilized to produce second-generation atlases that reflect the genuine molecular state of cells within both homeostatic and diseased tissues.

\section{Limitations of study}

In this study we have demonstrated the advantages of implementing specialized protocols for capturing accurately the molecular profile of cells both in homeostatic tissue and in response to injury. The two protocols that we propose (in situ paraformaldehyde-fixation of cells (Machado et al., 2017) and instant nuclei extraction from muscle (Dos Santos et al., 2020)), demonstrate 
great advantages yet have certain limitations. Due to their chemical properties, aldehyde-fixed cells were incompatible with high-throughput 10x Genomics single-cell analysis. To overcome that, we performed single-nuclei RNA-seq that results in lower yields and decreased gene coverage compared to single-cell approaches. Moreover, despite producing precise homeostatic atlases, single-nuclei RNAseq lack spatial information.

In addition, this study investigated the effect of dissociation on many cell-types and focused on MuSCs as a paradigm for stem cell fate transition. The functional role of this cellular response should be studied on other cell types, including stem cells and terminally differentiated cells. Moreover, we analysed two highly regenerative tissues from one mammalian organism. To strengthen the conservation aspect of the stress-core, our field would benefit from a systematic study of this phenomenon across tissues and organisms, including humans, under normal and pathological conditions. 


\section{Acknowledgements}

We would like to thank Hanne Grosemans for performing the muscle injuries. We thank Brigitte Izac and Benjamin Saintpierre, Institut Cochin (Université de Paris, Institut Cochin, CNRS, INSERM, F-75014 Paris, France) for single-nucleus sequencing libraries and data processing. We also thank Erica Kimber for her elaborative editing of the manuscript. FR laboratory receives funding from Association Française contre les Myopathies (AFM) via TRANSLAMUSCLE (PROJECT 22946), Labex REVIVE (ANR-10-LABX-73), Agence Nationale pour la Recherche (ANR) grant Bone-muscle-repair (ANR-13-BSV1-0011-02), Satnet (ANR-15-CE13-0011-01), BMP-MyoStem (ANR-16-CE14-0002-03), MyoStemVasc (ANR-17-CE14-0018-01), muscleXTRA (ANR-19-CE13-0010), FRM ECO201806006793, and RHU CARMMA (ANR-15-RHUS-0003). Pa.M laboratory receives funding from ANR-16-CE14-0032-01 and AFM 21711. T.V. and J.V.H. are supported by KU Leuven (SymBioSys, C14/18/092) and the Research Foundation Flanders (FWO, G092415N and I001818N).

\section{Author contributions}

Designed experiments, L.M., P.G., M.D.S, J.C., Ph.M. and F.R.; Performed experiments, L.M., P.G., M.D.S, F.C., J.C., J.V.H. and Ph.M.; Interpreted data, L.M., P.G., J.C., Ph.M. and F.R.; Bioinformatic analysis L.M., J.C., H.V. and R.L. Wrote the manuscript, L.M., P.G., Ph.M. and F.R.; Funding Acquisition, M.S., T.V., JM.P., Pa.M., Ph.M. and F.R.; Supervision, Ph.M. and F.R.

\section{Declaration of interests}

The authors declare no competing interests. 
Figure 1. Definition of a core stress signature in response to cell dissociation.

(A) Liver and hindlimb skeletal muscle single nuclei were FACS-isolated based on DAPI from either intact tissues or after $2 \mathrm{~h}$ enzymatic dissociation at $37^{\circ} \mathrm{C}$. Intact muscle: 7,951 nuclei from 2 biological replicates. Digested muscle: 8,640 nuclei from 1 biological replicate. Each muscle biological replicate is a pool of TAs from 4 mice. Intact liver: 8,996 nuclei from 1 biological replicate. Digested liver: 3,762 nuclei from 1 biological replicate. Each liver biological replicate is a pool of livers from 3 mice.

(B) Uniform Manifold Approximation and Projection (UMAP) plots displaying the different cell populations in intact and digested muscle and liver. Abbreviations: Endo: endothelial cells; Hepato: hepatocytes; T: T cells; B: B cells; FAPs: fibro- adipogenic progenitors; Teno: tenocytes; SM: smooth-muscle cells; Macro: macrophages; MuSCs: skeletal muscle stem cells; Lymph: lymphatic cells; Adipo: adipocytes; Chol: cholangiocytes.

(C) UMAP plots displaying the different populations inferred from intact (blue) or dissociated (red) muscle (left) and liver (right) single-nucleus transcriptomes without data integration. Differences were observed in the relative abundance of the populations: Myonuclei: digested 6\%, intact 64\%; Endothelial muscle: digested 29\%; intact 1\%; Endothelial liver: digested 36\%, intact $4 \%$.

(D) Histogram representing the distribution of genes induced by dissociation in the 10 main cell populations. Number of genes within each segment is indicated.

(E) Genes up-regulated by at least 7 populations composed the 98-genes Stress core. Selected examples are displayed in the table.

(F) Gene ontology analysis of the Stress core using the biological process category. Selected terms with corrected $p$-value $<0.05$ are displayed and ranked by fold-change.

(G) UMAP plot representing the Stress Index of every cell from the published Tabula Muris Smart-Seq2 dataset.

(H) UMAP plot representing the calculated digestion time at $37^{\circ} \mathrm{C}$ (see Methods) of every cell from the Tabula Muris Smart-Seq2 dataset (53,760 cells). Note the correlation between high digestion time and high Stress Index (Spearman correlation coefficient: 0.51).

(I) Median Stress Index in different cell types. Median digestion time at $37{ }^{\circ} \mathrm{C}$ is color-coded (grey/blue gradient). 


\section{Figure 2. Stress signature during in vivo tissue injury.}

(A) Nuclei from intact and 4h-injured Tibialis Anterior (TA) muscle and liver were FACSisolated based on DAPI and analyzed using 10X Genomics. Intact muscle: 7,951 nuclei from 2 biological replicates. Injured muscle: 1,618 nuclei from 2 biological replicates. Each muscle biological replicate is a pool of TAs from 4 mice. Intact liver: 8,996 nuclei from 1 biological replicate. Injured liver: 6,271 nuclei from 1 biological replicate. Each liver biological replicate is a pool of livers from 3 mice.

(B) UMAP plots displaying the different populations inferred from intact and injured liver (top) and muscle (bottom) single-nucleus RNA-seq after data integration using Seurat3. Abbreviations: Endo: endothelial cells; T: T cells; B: B cells; FAPs: fibro- adipogenic progenitors; Teno: tenocytes; SM: smooth-muscle cells; Macro: macrophages; MuSCs: skeletal muscle stem cells; Lymph: lymphatic cells; Adipo: adipocytes; Chol: cholangiocytes.

(C) UMAP plots displaying the different populations inferred from intact (blue) or injured (red) liver (top) and muscle (bottom) single-nucleus transcriptomes without data integration. Red box inset in muscle UMAP designates the MuSC and tenocyte populations

(D) UMAP plots representing the Stress Index among liver (top) and muscle (bottom) intact and injured cells.

(E) Graphical scheme of single-MuSC RNAseq post injury experiment: TA muscles of Tg:Pax7-nGFP mice were injected with $\mathrm{BaCl}_{2}$ and single MuSCs were isolated at 0,2 and $4 \mathrm{~h}$ post-injury using the $i S i F i$ methodology. 280 cells were obtained from 6 mice ( 2 biological replicates per time-point).

(F) PCA of resting (T0) and in vivo activated MuSCs (T2 and T4). PC1 and PC2 represent 4\% and $3 \%$ of variance explained, respectively.

(G) Pseudotime-analysis (Slingshot) shows the differentiation trajectory of MuSCs during in vivo activation. Pseudotime values are color-graded from dark blue to dark red for undifferentiated to differentiated cellular state, respectively.

(H) Kinetics of the stress response during muscle injury. Representation of the Stress Index $(\log 2)$ from the shared Stress core genes into each single-MuSC (gray dot), ordered by pseudotime value. Polynomial second order regression shown in red and standard error in grey. 


\section{Figure 3. Time-course analysis reveals the kinetics of MuSCs quiescence exit.}

(A) Graphical scheme of the time-course experiment: MuSCs from forelimbs and hindlimbs of Tg:Pax7-nGFP mice were fixed with ice-cold $0.5 \%$ paraformaldehyde at different time-points during the enzymatic digestion and sorted for GFP for RNA extraction and sequencing. 3 to 4 biological replicates were used per time-point for a total of 24 mice analyzed for the experiment.

(B) Principal component (PC) analysis during MuSCs ex vivo dissociation delineating the transcriptional trajectories during early activation. Trend line and IC-75 have been added for visualization. PC1, PC2 and PC3 represent $27,10 \%$ and $8 \%$ of the variance explained, respectively.

(C) MA plots during MuSCs ex vivo dissociation. Colored dots represent statistically differentially expressed genes with $\mathrm{p}<0.05$ and absolute $\mathrm{FC}>2$ (red dots) or $<0.5$ (blue dots), using DEseq2 against T0 for each time-point. The number of up- and down- regulated genes is indicated in each panel.

(D) Hierarchical clustering of gene expression during MuSC ex vivo dissociation reveals transcriptional modules of co-expressed genes. The clusters were extracted from the row dendrogram using $k=5$.

(E) Mean expression of specific genes per time-point. Gene symbols in red are members of the Stress core.

(F) Clusters of upregulated (clusters 1, 2, and 3) and downregulated (clusters 4 and 5) genes as defined by the hierarchical. Linear regression with second-order polynomial was performed on the mean gene expression per time-point for each cluster. Samples are ordered from T0 to T120. Standard error is displayed in grey.

(G) Projection of the ex vivo dissociated MuSCs using gene loadings of the first two Principal Components from the injury-activated MuSC; dissociated MuSCs are positioned according to their digestion time from $\mathrm{T} 0$ to $\mathrm{T} 120$.

(H) Mean normalized counts per million of the genes contained in the 5 cluster modules of the ex vivo bulk RNA-seq dataset (Fig. 3D) compared to the mean normalized counts per million of the same genes into the in vivo injury-activated MuSCs. 


\section{Figure 4. Functional assessment of the stress response in MuSCs exit from quiescence}

(A) Effect of DFMO on the activation and differentiation of freshly isolated MuSCs from Tg:Pax7-nGFP mice. Cell cycle entry was quantified by EdU incorporation for $40 \mathrm{~h}$ after plating, and MuSC differentiation by PAX7 (GFP) and Myogenin positive cells at $72 \mathrm{~h}$ after plating ( $\mathrm{n}=4$ mice per condition).

(B) (left) Representative images of EdU and nuclear GFP after $40 \mathrm{~h}$ in culture in the absence (control) or presence of $2 \mu \mathrm{M}$ DFMO. (right) MuSCs stained against GFP and the differentiation Myogenin after $72 \mathrm{~h}$ in culture.

(C) Immunostaining and quantification for MYOD and EdU on dissociated muscle cells after $45 \mathrm{~h}$ in culture in the presence of the ERK1/2 inhibitor SCH772984 or DMSO vehicle control. MuSCs were detected by GFP in control (Tg:Pax7-nGFP) and NICD-ires-GFP expression $\left(\right.$ Pax $\left.7^{\text {CreERT2 }} ; R 26^{\text {stop-NICD-ires- } n G F P}\right),(\mathrm{n}=4$ mice per genotype and per condition).

(D) Immunostaining and quantification for PAX7, EdU (24 h chase) and NICD (GFP) on cultured muscle cells from $\operatorname{Pax} 7^{\mathrm{CreERT2}} ; \mathrm{R}^{2} 6^{\text {stop-NICD-ires-nGFP }}$ mice with or without SCH772984 after plating for $72 \mathrm{~h}$; * EdU ${ }^{-}$cell; ( $\mathrm{n}=4$ mice per genotype and per condition).

(E) Inhibition of ERK1/2 signaling during the dissociation process. Efficiency of inhibition was evaluated in MuSCs by qRT-PCR for MAPK target genes on freshly isolated $\mathrm{GFP}^{+}$cells. Gene expression was normalized to $\operatorname{Tbp}$ ( $\mathrm{n}=3$ mice per condition).

(F) Representative images of cells from Tg:Pax7-nGFP mice stained for MYOD, EdU, and GFP after $45 \mathrm{~h}$ in culture; EdU added at $\mathrm{t}=0$. ( $\mathrm{n}=4$ mice per condition).

Independent student $\mathrm{t}$-test was performed. ns not statistically significant $* \mathrm{p}<0.05, * * \mathrm{p}<0.01$, $* * * \mathrm{p}<0.001$. Scale bar $15 \mu \mathrm{m}$. 


\section{Resource availability}

$\underline{\text { Lead contact }}$

Further information and requests for resources and reagents should be directed to and will be fulfilled by the Lead Contact, Frederic Relaix (frederic.relaix@inserm.fr)

$\underline{\text { Materials availability }}$

This study did not generate new unique reagents.

$\underline{\text { Data and code availability }}$

All single-cell, single-nuclei and bulk RNA-sequencing datasets generated during this study are available at Gene Expression Omnibus (GEO), accession number GSE163856.

\section{Experimental model and subject details}

$\underline{\text { Animals }}$

The following mouse lines were kindly provided by the corresponding laboratories as described: Tg:Pax7-nGFP (S. Tajbakhsh; Sambasivan et al., 2009), R26R $R^{\text {stop-NICD-nGFP }}$ (D. Melton; Jackson Laboratories, stock 008159; Murtaugh et al., 2003), Pax7_CreERT2 (G. Kardon; Jackson Laboratories, stock 017763; Murphy and Kardon, 2011). Animals were handled as per

French and European Community guidelines and protocols were approved by the ethics committee at the French Ministry (Project No: 20-027 \#24357).

\section{$\underline{\text { Cell culture of primary muscle cells }}$}

MuSCs were isolated by FACS from male and female Tg:Pax7-nGFP mice and plated on Matrigel-coated (Corning, 354248), 8-chamber slides (Sarstedt, 94.6140.802) in growth medium (GM) composed of DMEM (GIBCO) with 20\% fetal bovine serum (FBS), 1\% penicillin/streptomycin (GIBCO), and supplemented with $5 \mathrm{ng} / \mathrm{ml}$ basic FGF (Peprotech, 45033 ) at $37^{\circ} \mathrm{C}$. Whole muscle bulk preparations were cultured on Matrigel-coated 8-chamber Sarstedt slides in $\mathrm{GM}$ at $37^{\circ} \mathrm{C}$ in the presence of $10 \mu \mathrm{M}$ EdU. Muscles from Tg:Pax7-nGFP mice were dissected and chopped on ice, then digested following standard procedures in the presence or absence of $2 \mu \mathrm{g} / \mathrm{mL} \mathrm{SCH772984} \mathrm{or} \mathrm{DMSO} \mathrm{control.} \mathrm{Digested} \mathrm{muscle} \mathrm{was} \mathrm{then}$ filtered through $100 \mu \mathrm{m}$ and $70 \mu \mathrm{m}$ cell strainers, spun down at $600 \mathrm{~g} / 5 \mathrm{~min}$, then resuspended in cold DMEM and filtered through a $40 \mu \mathrm{m}$ cell strainer and eventually spun down at $600 \mathrm{~g}$ for 5 min. All filtering steps were done on ice. For Pax7-CreERT2; R26 Stop-NICD-nGFP and Tg:Pax7$n G F P$ bulk muscle preparations, growth medium was supplemented with $5 \mathrm{ng} / \mathrm{mL}$ of basic FGF and cells were cultured in the presence of DMSO (control) or $1 \mu \mathrm{g} / \mathrm{ml} \mathrm{SCH772984}$. For ERK inhibition, cells were plated in the presence of the ERK1/2 inhibitor SCH772984 (Selleckchem, 
$\mathrm{S} 7101)$ at $1 \mu \mathrm{g} / \mathrm{ml}$ or DMSO, in the presence of $10 \mu \mathrm{M}$ 5-ethynyl-20-deoxyuridine (EdU), (Click-iT PLUS Kit C10640, Life Technologies). For ODC1 inhibition, cells were plated in the presence or absence of $2.5 \mathrm{mM}$ DFMO (Tocris, 2761) resuspended in DMEM with $10 \mu \mathrm{M}$ EdU for the first time point.

\section{Method details}

Muscle and liver injury

For muscle injury, mice were anaesthetized with an intraperitoneal injection of 1.6:1 ketamine and xylazine ( $2 \%$, VMD), $60 \mu \mathrm{l}$ per $20 \mathrm{~g}$ of bodyweight. Both TA muscles were injected with $50 \mu \mathrm{l}$ of $1.2 \% \mathrm{BaCl} 2$ (Sigma, 202738). For liver injury, mice received an intraperitoneal injection of carbon tetrachloride $\left(\mathrm{CCl}_{4}\right.$, Sigma, 289116 at $0.5 \mathrm{ml} / \mathrm{kg}$ bodyweight, $1: 5$ dilution in olive oil) as described previously described (Teixeira-Clerc et al., 2010).

\section{$\underline{\text { Single-nucleus isolation }}$}

For the intact/dissociated muscle and liver atlases 6 tibialis anterior, gastrocnemius, soleus, plantaris, and extensor digitorum longus muscles as well as 3 whole liver from 3 8-week old female mice were used. For the intact/injured muscle atlas, 8 tibialis anterior muscles from 4 8 -week old female mice were used. Tissues were dissected and pulled in cold PBS with 0.2 $\mathrm{U} / \mu 1$ RNase inhibitor (Roche, 03335399001). PBS was removed and tissues were minced in 1 $\mathrm{ml}$ cold lysis buffer $(10 \mathrm{mM}$ Tris- $\mathrm{HCl}, 10 \mathrm{mM} \mathrm{NaCl}, 3 \mathrm{mM} \mathrm{MgCl} 2$, and $0.1 \%$ NonidetTM P40 in Nuclease-Free Water) with scissors. After $2 \mathrm{~min}, 4 \mathrm{ml}$ of cold lysis buffer was added and tissues were lysed for $3 \mathrm{~min}$ at $4{ }^{\circ} \mathrm{C} .9 \mathrm{ml}$ of cold wash buffer (PBS, BSA $2 \%$ and $0.2 \mathrm{U} / \mu 1$ RNase inhibitor) was subsequently added and the lysates were homogenized with 10 strokes of loose pestle using a $15 \mathrm{ml}$ Dounce homogenizer. The homogenates were filtered with $70 \mu \mathrm{m}$ and $40 \mu \mathrm{m}$ cells strainers. Nuclei were pelleted by centrifugation for $5 \mathrm{~min}\left(500 \mathrm{~g}, 4^{\circ} \mathrm{C}\right)$. Nuclei were washed in $1 \mathrm{ml}$ of cold wash buffer, transferred in a $1.5 \mathrm{ml}$ tube and centrifuged $5 \mathrm{~min}$ $\left(500 \mathrm{~g}, 4^{\circ} \mathrm{C}\right)$. The pellets were resuspended in $250 \mu \mathrm{l}$ of wash buffer and stained during $15 \mathrm{~min}$ in the dark at $4{ }^{\circ} \mathrm{C}$ with DAPI at $10 \mu \mathrm{g} / \mathrm{ml}$. The nuclei were therefore washed and spun down 5 $\min \left(500 \mathrm{~g}, 4^{\circ} \mathrm{C}\right)$, resuspended in $300 \mu \mathrm{l}$ of wash buffer and filtered with $30 \mu \mathrm{m}$ cell strainers. Nuclei were then FACS sorted for Hoechst to exclude debris with a BD FACSAria III and the BD FACSDIVA software. 


\section{$\underline{\text { Staining }}$}

For cell culture, following fixation (2\% paraformaldehyde (PFA), $20 \mathrm{~min}$ ), MuSCs were washed three times in PBS, permeabilized, and blocked using a blocking solution (BS) containing 5\% BSA (Jackson Laboratories 001-000-162) and 0.25\% Triton X-100 (Sigma) for $60 \mathrm{~min}$ at room temperature. The samples were subsequently washed three times with PBS and stained for EdU and Hoechst (EdU Click-iT PLUS Kit C10640, Life Technologies) following the manufacturer guidelines before a final wash and mounting. For tissue sections, dissected and injured TA muscles were immediately frozen in liquid-nitrogen-cooled isopentane and sectioned transversely at $8 \mu \mathrm{m}$. The sections were fixed for $10 \mathrm{~min}$ with $4 \%$ PFA, washed three times, permeabilized and blocked with BS for $1 \mathrm{~h}$ at RT before being incubated with antilaminin primary antibody (Sigma, L9393, 1:500) overnight. After three washes, the sections were incubated with the corresponding secondary antibodies and Hoechst (1:1000) for $1 \mathrm{~h}$ at RT.

\section{$\underline{\text { Western Blot }}$}

Hind limb muscles were dissected and directly processed or digested for $15 \mathrm{~min}$ at $37^{\circ} \mathrm{C}$ in $1 \mathrm{X}$ digestion solution. Before lysis, tissues were fixed in $0.5 \%$ PFA for $1 \mathrm{~h}$ at $4{ }^{\circ} \mathrm{C}$ and then washed 3 times in cold PBS (600 g, $5 \mathrm{~min}$ ). The samples where then re-digested for $2 \mathrm{~h}$ in $2 \mathrm{X}$ digestion solution, minus the initial digestion time, before being filtered successively through $100 \mu \mathrm{m}$ and $70 \mu \mathrm{m}$ cell strainers (MACS, 130-110-917 and 130-110-916, respectively), then spun down (600 g, $5 \mathrm{~min})$, resuspended in ice-cold DMEM and filtered through $40 \mu \mathrm{m}$ cell strainer (Corning, 352340) before a last centrifugation (600 g, $5 \mathrm{~min}$ ). For ERK inhibition during the dissociation, hind limb muscles from Tg:Pax7-nGFP mice were dissected and digested in the presence of $2 \mu \mathrm{g} / \mathrm{mL}$ SCH772984. DMSO was added in control samples. The cells were lysed using RIPA buffer: $50 \mu \mathrm{M}$ Tris $\mathrm{Hcl}$ pH 8,150 $\mu \mathrm{M} \mathrm{NaCl}, 1 \%$ NP40, 0.5\% Sodium Deoxycholate, $0.1 \%$ SDS, $1 \mu$ M EDTA pH 8, protease inhibitor cocktail (Merck, 4693159001) and phosSTOP (Merck, 4906845001). After BCA protein assay measurements, $800 \mathrm{ng}$ of protein per lane were loaded on a Bolt ${ }^{\mathrm{TM}}$ 4-12\% Bis-Tris Plus Gels (Thermofisher, NW04120BOX) for $1 \mathrm{~h}$ at $150 \mathrm{~V}$. The gel was washed once in $\mathrm{H}_{2} \mathrm{O}$ and fixed for $5 \mathrm{~min}$ in $20 \%$ ethanol. The proteins were then transferred on a membrane $(15 \mathrm{~V}, 7 \mathrm{~min})$ using the iBlot ${ }^{\mathrm{TM}} 2$ Transfer Stacks, PVDF, mini kit (Thermofisher, IB24002). The membrane was washed twice with PBST (0.1\% triton:PBS, 5 min), blocked with 5\% BSA in PBST for $1 \mathrm{~h}$ at RT with rotation. The membrane was incubated with primary antibodies overnight for ERK1/2 (EMD Millipore 06-182 rabbit polyclonal, 1:10000) and for phospho-ERK1/2 (Abcam ab50011-100 mouse, 1:1000) (Fig. S4D) (Cell 
signaling Technology, 9101, 1:1000) (Fig. S10A) in PBST. After two washes with PBST (5 min) the membrane was incubated with secondary antibodies (conjugated anti-rabbit PI-1000 ZD0821 and anti-mouse PI-2000-1 ZC1212 from Vector Laboratories, 1:5000) for $1 \mathrm{~h}$ at RT. Proteins were revealed using SuperSignal ${ }^{\text {TM }}$ West Femto Maximum Sensitivity Substrate (Thermofisher, 34094) for $3 \mathrm{~min}$ at RT.

\section{$\underline{\text { In Situ Fixation treatment and reagents }}$}

For ex vivo dissociation, after mouse sacrifice muscles were dissected (hindlimb and forelimb) and minced in small pieces. Tissue pool from two mice were separated in 6 groups (T0, T15, T30, T60, T90, and T120). T0 samples were prepared according to the original iSiFi protocol (Machado et al., 2017). Briefly, the samples were fixed for $1 \mathrm{~h}$ in $0.5 \%$ PFA, washed 3 times in ice-cold PBS and digested for $2 \mathrm{~h}$ at $37{ }^{\circ} \mathrm{C}$ with agitation in $2 \mathrm{X}$ digestion solution: Dispase II, $6 \mathrm{U} / \mathrm{ml}$ (Roche, 4942078001), Collagenase A $1 \mathrm{U} / \mathrm{ml}$ (Roche, 10103586001) and 0.2\% BSA:DMEM. T15, T30, T60, T90 and T120 samples were digested for 15, 30, 60, 90 and 120 min respectively in $1 \mathrm{X}$ digestion solution: Dispase II, $3 \mathrm{U} / \mathrm{ml}$ (Roche, 4942078001), Collagenase A $0.5 \mathrm{U} / \mathrm{ml}$ (Roche, 10103586001 ) and $0.2 \% \mathrm{BSA} / \mathrm{DMEM}$ at $37^{\circ} \mathrm{C}$ with agitation. The samples were then spun down (600 g, $5 \mathrm{~min})$ and resuspended in ice-cold 0.5\% PFA and incubated for $1 \mathrm{~h}$ at $4{ }^{\circ} \mathrm{C}$ with gentle agitation to fix the cells. The samples were washed 3 time with ice-cold PBS (600 g, $5 \mathrm{~min}$ ) and resuspended in $2 \mathrm{X}$ digestion solution to terminate digestion for 105, 90, 60 and $30 \mathrm{~min}$ for T15, T30, T60 and T90 samples respectively. T120 samples were not re-digested. At this point, all the samples were filled with DMEM (Gibco, 41966-029) and filtered successively through $100 \mu \mathrm{m}$ and $70 \mu \mathrm{m}$ cell strainers (MACS, 130110-917 and 130-110-916 respectively) then span down (600 g, $5 \mathrm{~min})$, resuspended in ice-cold DMEM and filtered through $40 \mu \mathrm{m}$ cell strainer (Corning, 352340) before a last centrifugation (600 g, $5 \mathrm{~min}$ ) and resuspension in 0.2\% BSA/DMEM for cell sorting.

For the experiment comparing T60 MuSCs in the supernatant to intact tissue pieces, T0, T60 and T120 samples were obtained from the dissection of hindlimbs and forelimbs from the same mice. For this experiment T0 and T120 samples were processed as indicated above. T60 samples were incubated for $60 \mathrm{~min}$ in $1 \mathrm{X}$ digestion solution. The samples were then separated simply with gravity by incubating the tube $(50 \mathrm{ml}$ conical $)$ vertically at RT for $5 \mathrm{~min}$ to pellet intact tissue pieces and to carefully pass the supernatant successively through 100, 70 and 40 $\mu \mathrm{m}$ filters (references above) to obtain dissociated cells. Both samples were filled with ice-cold DMEM, span down (600 g, $5 \mathrm{~min}$ ) and resuspended in ice-cold $0.5 \%$ PFA for $1 \mathrm{~h}$ at $4{ }^{\circ} \mathrm{C}$ with 
agitation. The T60-pellet samples were then re-digested for $60 \mathrm{~min}$ in $2 \mathrm{X}$ digestion solution. All samples were then filtered as indicated above.

For in vivo activation, after mouse sacrifice injured TA muscles were dissected and minced in small pieces. The samples were prepared according to the original iSiFi protocol (Machado et al., 2017), with the following modification: $0.5 \mathrm{M}$ glycine:PBS was used in the first postPFA wash.

\section{$\underline{\text { RNA extraction }}$}

For ex vivo dissociation time-course, in vivo activation control and ex vivo ERK1/2 inhibition during dissociation RT-qPCR, the cells were sorted directly in lysis buffer from the Quick RNA FFPE kit (Zymo, R1008) and the RNA extracted following the manufacturer guidelines (without the tissue digestion step). For T60 supernatant/pellet RT-qPCR, the cells were sorted directly in lysis buffer from the RecoverAll FFPE kit (Thermo, AM1975) and the RNA extracted following the manufacturer guidelines (without the tissue digestion step, without the incubation step at $80^{\circ} \mathrm{C}$ and with the incubation step at $50^{\circ} \mathrm{C}$ for $1 \mathrm{~h}$ instead of $15 \mathrm{~min}$ ). For in vivo activation time-course, Pax7-nGFP cells were sorted single-cell by FACS in 96 well plates (4titude, 4ti-0960). Each well contained 2.5 $\mu 1$ PKD buffer (Qiagen, 1034963) supplemented with 1:16 proteinase K (Qiagen, 19131). Prior to RNA separation, plates were decrosslinked for $1 \mathrm{~h}$ at $56^{\circ} \mathrm{C}$. RNA separation was performed on a Hamilton STAR according to the G\&T-seq protocol (Macaulay et al., 2015). Briefly, oligo-dt30VN-labeled beads and wash buffer were prepared. $10 \mu 1$ of beads were added to every well with the liquid-handling robot and incubated for $20 \mathrm{~min}$ at RT while mixing (2,000 rpm). Thereafter, the beads were washed twice with wash buffer and $5 \mu 1$ of Reverse Transcriptase master mix was added to every well of the bead-containing 96-well plate.

\section{$\underline{\text { RT-qPCR }}$}

Reverse transcription was performed using the SuperScript IV VILO Master Mix (Thermofisher, 11756050) following the manufacturer's guidelines. RT-qPCR was performed using the Power SYBR Green PCR Master Mix (Applied Biosystems, 4367659).

\section{Library preparation}

- For snRNA-seq:

Single-cell Gel Bead-In-EMulsions (GEMs) were generated using a Chromium Controller instrument (10x Genomics). Sequencing libraries were prepared using Chromium Single Cell 
3' Reagent Kits (10x Genomics, 1000074), according to the manufacturer's instructions. Briefly, GEM-RT was performed in a thermal cycler: $53{ }^{\circ} \mathrm{C}$ for $45 \mathrm{~min}, 85^{\circ} \mathrm{C}$ for 5 min. Post GEM-RT Cleanup using DynaBeads MyOne Silane Beads (Thermofisher, 37002D) was followed by cDNA amplification $\left(98^{\circ} \mathrm{C}\right.$ for $3 \mathrm{~min}$, cycled 12 $\mathrm{x} 98{ }^{\circ} \mathrm{C}$ for $15 \mathrm{~s}, 67^{\circ} \mathrm{C}$ for $20 \mathrm{~s}, 72{ }^{\circ} \mathrm{C}$ for $1 \mathrm{~min}$, and $72{ }^{\circ} \mathrm{C} 1 \mathrm{~min}$ ). After a cleanup with SPRIselect Reagent Kit (Beckman, C10640) and fragment size estimation with High Sensitivity ${ }^{\text {TM }}$ HS DNA kit runned on 2100 Bioanalyzer (Agilent, 5067-4626), the libraries were constructed by performing the following steps: fragmentation, end-repair, A-tailing, SPRIselect cleanup, adaptor ligation, SPRIselect cleanup, sample index PCR, and SPRIselect size selection.

The fragment size estimation of the resulting libraries were assessed with High Sensitivity ${ }^{\mathrm{TM}}$ HS DNA kit runned on 2100 Bioanalyzer and quantified using the Qubit ${ }^{\mathrm{TM}}$ dsDNA High Sensitivity HS assay (Thermofisher, Q32851). Libraries were then sequenced by pair with a HighOutput flowcel using an Illumina Nextseq 500 with the following mode: 26 base-pairs (bp) (10X Index + UMI), 8 bp (i7 Index) and 57 bp (Read 2).

\section{- For Bulk RNA-seq:}

Directional libraries were prepared using the Smarter Stranded Total RNA-Seq kit- Pico Input Mammalian following the manufacturer's instructions (Clontech, 635005). The quality of all libraries was checked with the DNA-1000 kit (Agilent) on a 2100 Bioanalyzer and quantification was performed with Quant-It assays on a Qubit 3.0 fluorometer (Invitrogen). Clusters were generated for the resulting libraries, with Illumina HiSeq SR Cluster Kit v4 reagents (Illumina, GD-401-4001). Sequencing was performed with the Illumina HiSeq 2500 system and HiSeq SBS kit v4 reagents. Runs were carried out over 65 cycles, including seven indexing cycles, to obtain $65 \mathrm{bp}$ single-end reads. Sequencing data were processed with Illumina Pipeline software (Casava version 1.9).

- For scRNA-seq:

cDNA libraries were generated based on the Smart-seq2 protocol (Picelli et al., 2014). To increase RNA extraction from fixed cells, we sorted single cells into 96-well tubes containing $5 \mu \mathrm{L}$ of PKD Buffer (Qiagen) with 1:16 Proteinase K Solution (Qiagen), as previously described (Thomsen et al., 2016). Briefly, mRNA was reverse transcribed and cDNA was amplified via PCR for 27 cycles. Amplification was done with KAPA HIFI Hot Start ReadyMix (Roche, 07958919001) and purification by magnetic beads (CleanNA CPCR). Quantity and quality of cDNA was assessed with the quantifluor RNA system (Promega E3310) and Agilent 
2100 BioAnalyzer with a high-sensitivity chip. Library preparation was done with the Nextera XT library prep and index kit (Illumina FC-131-1096 and FC-131-2001). 100 pg of cDNA was tagmented by transposase Tn5 and amplified with dual-index primers (i7 and i5, Illumina, 12 cycles). Reagents were mixed together by the Echo 555 (Labcyte) and pooled-nextera XT libraries were purified. 384 single-cell libraries were pooled together and sequenced single-end $50 \mathrm{bp}$ on a single lane of a HiSeq4000 (Illumina). All results related to scRNA-seq are based on 2 pooled biological replicates per group, experiments were performed on the same day.

\section{Quantification and statistical analysis}

\section{High-throughput datasets processing}

$$
\text { - } \quad \text { snRNA-seq }
$$

The sequencing data was processed into transcript count tables with the Cell Ranger Single Cell Software Suite 3.0 .2 by $10 \mathrm{X}$ Genomics. Raw base call files from the Nextseq 500 were demultiplexed with the cellranger mkfastq pipeline into library-specific FASTQ files. The FASTQ files for each library were then processed independently with the cellranger count pipeline. This pipeline used STAR to align cDNA reads to the Mus musculus transcriptome (Sequence: GRCm38, Mouse reference provided by 10X.). Once aligned, barcodes associated with these reads - cell identifiers and Unique Molecular Identifiers (UMIs), underwent filtering and correction. Reads associated with retained barcodes were quantified and used to build a transcript count table. We re-run this same pipeline with the pre-mRNA reference, build with cellranger mkgtf and cellranger mkref. Quality control on aligned and counted reads was performed keeping cells with $>500$ reads, $>250$ detected genes and less than $15 \%$ mitochondrial genes. The subsequent visualizations, clustering and differential expression tests were performed in R (v 3.4.3) using Seurat (v3.0.2) (Stuart et al., 2019), Pooling of intact and dissociated nuclei was performed by merging the raw data per tissue followed by normalisation.

- Bulk RNA-seq datasets processing

Bioinformatics analysis was performed using the RNA-seq pipeline from Sequana (Cokelaer et al., 2017). Reads were cleaned of adapter sequences and low-quality sequences using cutadapt version 1.11 (Martin, 2011). Only sequences at least $25 \mathrm{nt}$ in length were considered for further analysis. STAR version 2.5.0a (Dobin et al., 2013), with default parameters, was used for alignment on the reference genome (Mus musculus GRCm38 assembly from Ensembl release 87). Genes were counted using featureCounts version 1.4.6-p3 (Liao et al., 2013) from Subreads package (parameters: -t exon -g gene_id -s 1) under gencode mm10 annotation version M11. 
Count data were analyzed using R version 3.4.3 and the Bioconductor package DESeq2 version 1.18.1 (Love et al., 2014). Due to putative genomic DNA contamination, only genes with an average number of reads greater than 150 were used as input of the differential analysis $(\mathrm{N}=8059$ genes). The normalization was performed using the "shorth" parameter and dispersion estimation was performed using the default parameters. A generalized linear model was set in order to test for the differential expression between the different time points. For each pairwise comparison, the independent filtering algorithm was applied and raw p-values were adjusted for multiple testing according to the Benjamini and Hochberg $(\mathrm{BH})$ procedure (Benjamini and Hochberg, 1995). Genes with an adjusted p-value lower than 0.05 and an absolute fold-change higher than 2 were then considered differentially expressed.

- $\quad$ scRNA-seq downstream analysis

Fastq files contained 50-bp-long single-end sequenced tags (reads) from 384 cells. Each were trimmed with cutadapt 1.5 with the parameters '-q 20,20 --minimum-length 35 " and the nextera adapter sequence. The retained tags were aligned to the Ensembl 84 (Yates et al., 2016) gene annotation of the NCBI38/mm10 mouse genome using STAR 2.4.0 with the parameters '-outSAMunmapped Within -runThreadN ${ }^{44}$--genomeDir \{reference_genome $\}$-readFilesCommand zcat --outSAMtype BAM SortedByCoordinate'. The number of tags per gene was calculated using htseq-count 0.6.0 (Anders et al., 2015) with the parameters 'format=bam --order=pos --mode=intersection-strict $\quad$--stranded=no $\quad$--type=exon -idattr=gene_id \{input.bam $\}$ \{reference_gtf $\}>\{$ output.count $\}$ '. Quality control on alignment and counting was done with ngsplot ${ }^{44}$ with parameters '-G mm10 -R genebody -C \{input.bam\} -O \{results_dir\}/genecoverage/ \{wildcards.sample\}.gene -F rnaseq' and multiqc (Ewels et al., 2016). Quality control on aligned and counted reads was performed with Scater 1.8.4 (McCarthy et al., 2017), cells with $<200,000$ reads, $<900$ detected genes, $>6$ percent mitochondrial genes and $>0.75$ percent of spike-in ERCCs. Read normalization was done with Scran 1.8.4. Reads were normalized separately from ERCCs. For each gene, expression estimates per gene were expressed as log-transformed counts by taking the $\log ^{2}$ (counts +1 ). We used the top 500 highest variable genes to obtain a 2D representation of the cells, while maintaining the similarity relationships between them using PCA as implemented in the package Scater 1.8.4 (McCarthy et al., 2017). The trend line and IC-75 were calculated using the function geom_smooth() in R using the following parameters: method="glm", formula = y $\sim \operatorname{poly}(\mathrm{x}, 2)$, level=0.75, alpha=0.04. All data analysis was conducted in Python v3.6 (Python software foundation) or R v3.5.1 (CRAN). Differential expression was performed using MAST 
version 1.10 (Finak et al., 2015) and Monocle2 version 2.12.0 (Qiu et al., 2017) across all time-points.

\section{$\underline{\text { Pseudotime analysis }}$}

Satellite cells are reported to display a linear differentiation trajectory during the first hours after injury (De Micheli et al., 2020). Therefore, we performed single-cell trajectory analysis with Slingshot v1.4 (Street et al., 2018), shown in benchmarks to be the most optimal trajectory inference method for linear single-cell trajectories (Saelens et al., 2019). A matrix containing log normalized counts from 280 single satellite cells over three different timepoints was used to calculate the transcriptional differentiation path. Slingshot consists of three main steps. First a minimum spanning tree on the predefined clusters resembling different timepoints is constructed, this was done on the top five principal components. It builds a rough representation of the lineage trajectory that is then smoothened out in the second step, here, simultaneous principal curves are used to obtain smooth representations. Third, pseudotime values for each cell were calculated by orthogonal projection onto the smoothened lineage curve.

\section{$\underline{\text { Comparison of in vivo scRNA-seq with ex vivo bulk RNAseq data }}$}

In order to compare the in vivo single-cell RNAseq data with ex vivo bulk RNAseq data, we exported the gene loadings of the first two principal components from the single-cell RNAseq data and multiplied this by the scaled normalized expression values of the bulk RNAseq data. The single-cell RNAseq matrix consisted of the principal components as rows and genes as columns, while the bulk RNAseq matrix $(\mathrm{N})$ consisted of genes as rows and replicates as columns. Matrix multiplication yielded a matrix with components as rows and replicates as columns. The first two projected principal components were then plotted per timepoint of the bulk RNAseq data (Fig. 3G).

For comparison of gene cluster modules of the bulk RNAseq data described in Figure $3 \mathrm{H}$, we summed raw counts of the single-cell RNAseq data per replicate yielding two pseudobulks per timepoint. Bulk and pseudobulk data was combined and normalized for counts per million $(\mathrm{CPM})$, genes contained in the different gene clusters were then averaged per replicate and visualized as a linear model (avg CPM $\sim$ Time grouped for Experiment and gene clusters). To find out if gene clusters portrayed differences between experiments independently on time we performed an analysis of covariance test (ANCOVA) and computed the pairwise comparison between experiment groups per gene cluster by avg CPM $\sim$ Experiment*Time with Bonferroni correction as post-hoc test (Fig. S9C). 


\section{Associations with Tabula-Muris scRNA-seq}

The Tabula Muris droplet and Smart-Seq2 datasets were loaded from the TabulaMuris $\mathrm{R}$ package (v1.0) analyzed and visualized using Seurat. The Stress Index was calculated using the Seurat function "AddModuleScore" using the Stress response core from Figure S4B as a feature set. The Tabula Muris tissue digestion time were inferred from the original paper supplemental methods (supplemental Table 1). An arbitrary conversion factor of 0.5 and 0.2 were applied to correct kinetics of digestion steps at RT or on ice, respectively. The sum of all corrected sequential enzymatic digestion times for each cell was used to define the digestion time at $37^{\circ} \mathrm{C}$. The relative gene expression on muscle stem cells in each dataset shown in Figure S4J (iSiFi single-cell RNA-seq, snRNA-seq and Tabula Muris scRNAseq) was analyzed and visualized using Seurat.

\section{$\underline{\text { Statistical analysis }}$}

For comparison between two groups, unpaired Student's t test was performed to calculate $p$ values and to determine statistically significant differences $(* \mathrm{p}<0.05 ; * * \mathrm{p}<0.01 ; * * * \mathrm{p}<$ $0.001)$.

- Supplementary Table ST1. List of Stress core genes. Related to Figure 1.

- Supplementary Table ST2. Summary of the digestion time of different tissues analyzed by the Tabula Muris consortium. Related to Figure 1.

- Supplementary Table ST3. Sequence of RT-qPCR oligonucleotides. Related to Figure 4, Figure S3, and Figure S4. 


\section{References}

Adam, M., Potter, A.S., and Potter, S.S. (2017). Psychrophilic proteases dramatically reduce single cell RNA-seq artifacts : A molecular atlas of kidney development.

Anders, S., Pyl, P.T., and Huber, W. (2015). HTSeq-A Python framework to work with high-throughput sequencing data. Bioinformatics.

Bakken, T.E., Hodge, R.D., Miller, J.A., Yao, Z., Nguyen, T.N., Aevermann, B., Barkan, E., Bertagnolli, D., Casper, T., Dee, N., et al. (2018). Single-nucleus and single-cell transcriptomes compared in matched cortical cell types. PLoS One 13, e0209648-e0209648. Barton, K., Muthusamy, N., Chanyangam, M., Fischer, C., Clendenin, C., and Leiden, J.M. (1996). Defective thymocyte proliferation and IL-2 production in transgenic mice expressing a dominant-negative form of CREB. Nature 379, 81-85.

Benjamini, Y., and Hochberg, Y. (1995). Controlling the false discovery rate: a practical and powerful approach to multiple testing. J. R. Stat. Soc. B 57, 289-300.

Bohmann, D., Bos, T.J., Admon, A., Nishimura, T., Vogt, P.K., and Tjian, R. (1987).

Human proto-oncogene c-jun encodes a DNA binding protein with structural and functional properties of transcription factor AP-1. Science (80-. ).

Brink, S.C. van den, Sage, F., Vértesy, Á., Spanjaard, B., Peterson-Maduro, J., Baron, C.S., Robin, C., and Oudenaarden, \& A. van (2017). Single-cell sequencing reveals dissociationinduced gene expression in tissue subpopulations. 14 .

Camps, J., Breuls, N., Sifrim, A., Giarratana, N., Corvelyn, M., Danti, L., Grosemans, H., Vanuytven, S., Thiry, I., Belicchi, M., et al. (2020). Interstitial Cell Remodeling Promotes Aberrant Adipogenesis in Dystrophic Muscles. Cell Rep. 31, 107597.

Casar, J.C., McKechnie, B.A., Fallon, J.R., Young, M.F., and Brandan, E. (2004). Transient up-regulation of biglycan during skeletal muscle regeneration: Delayed fiber growth along with decorin increase in biglycan-deficient mice. Dev. Biol.

Chakkalakal, J. V, Jones, K.M., Basson, M.A., and Brack, A.S. (2012). The aged niche disrupts muscle stem cell quiescence. Nature 490, 355-360.

Cokelaer, T., Desvillechabrol, D., Legendre, R., and Cardon, M. (2017). ' Sequana ': a Set of Snakemake NGS pipelines. 2, 1-2.

Contreras, O., Cruz-Soca, M., Theret, M., Soliman, H., Tung, L.W., Groppa, E., Rossi, F.M., and Brandan, E. (2019). Cross-talk between TGF- $\beta$ and PDGFR $\alpha$ signaling pathways regulates the fate of stromal fibro-adipogenic progenitors. J. Cell Sci.

Dell'Orso, S., Juan, A.H., Ko, K.-D., Naz, F., Gutierrez-Cruz, G., Feng, X., and Sartorelli, V. (2019). Single-cell analysis of adult skeletal muscle stem cells in homeostatic and 
regenerative conditions. Development dev.174177.

Dobin, A., Davis, C.A., Schlesinger, F., Drenkow, J., Zaleski, C., Jha, S., Batut, P., Chaisson, M., and Gingeras, T.R. (2013). STAR: ultrafast universal RNA-seq aligner. Bioinformatics 29, 15-21.

Eng, C.-H.L., Lawson, M., Zhu, Q., Dries, R., Koulena, N., Takei, Y., Yun, J., Cronin, C., Karp, C., Yuan, G.-C., et al. (2019). Transcriptome-scale super-resolved imaging in tissues by RNA seqFISH+. Nature 568, 235-239.

Ewels, P., Magnusson, M., Lundin, S., and Käller, M. (2016). MultiQC: Summarize analysis results for multiple tools and samples in a single report. Bioinformatics.

Finak, G., McDavid, A., Yajima, M., Deng, J., Gersuk, V., Shalek, A.K., Slichter, C.K., Miller, H.W., McElrath, M.J., Prlic, M., et al. (2015). MAST: A flexible statistical framework for assessing transcriptional changes and characterizing heterogeneity in single-cell RNA sequencing data. Genome Biol.

Fuchs, E., and Blau, H.M. (2020). Tissue Stem Cells: Architects of Their Niches. Cell Stem Cell 27, 532-556.

Giordani, L., He, G.J., Negroni, E., Sakai, H., Law, J.Y.C., Siu, M.M., Wan, R., Corneau, A., Tajbakhsh, S., Cheung, T.H., et al. (2019). High-Dimensional Single-Cell Cartography

Reveals Novel Skeletal Muscle-Resident Cell Populations. Mol. Cell.

Ishikawa, T., Factor, V.M., Marquardt, J.U., Raggi, C., Seo, D., Kitade, M., Conner, E.A., and Thorgeirsson, S.S. (2012). Hepatocyte growth factor/c-met signaling is required for stem cell-mediated liver regeneration in mice. Hepatology.

Jessen, K.R., Mirsky, R., and Arthur-Farraj, P. (2015). The Role of Cell Plasticity in Tissue Repair: Adaptive Cellular Reprogramming. Dev. Cell.

Lacar, B., Linker, S.B., Jaeger, B.N., Krishnaswami, S.R., Barron, J.J., Kelder, M.J.E., Parylak, S.L., Paquola, A.C.M., Venepally, P., Novotny, M., et al. (2016). Nuclear RNA-seq of single neurons reveals molecular signatures of activation. Nat. Commun. 7, 11022. Liao, Y., Smyth, G.K., and Shi, W. (2013). featureCounts: an efficient general purpose program for assigning sequence reads to genomic features. Bioinformatics 30, 923-930. Love, M.I., Huber, W., and Anders, S. (2014). Moderated estimation of fold change and dispersion for RNA-seq data with DESeq2. Genome Biol. 15, 550.

Macaulay, I.C., Haerty, W., Kumar, P., Li, Y.I., Hu, T.X., Teng, M.J., Goolam, M., Saurat, N., Coupland, P., Shirley, L.M., et al. (2015). G\&T-seq: Parallel sequencing of single-cell genomes and transcriptomes. Nat. Methods.

Machado, L., Esteves de Lima, J., Fabre, O., Proux, C., Legendre, R., Szegedi, A., Varet, H., 
Ingerslev, L.R., Barrès, R., Relaix, F., et al. (2017). In Situ Fixation Redefines Quiescence and Early Activation of Skeletal Muscle Stem Cells. Cell Rep. 21.

Mandal, S., Mandal, A., Johansson, H.E., Orjalo, A. V, and Park, M.H. (2013). Depletion of cellular polyamines, spermidine and spermine, causes a total arrest in translation and growth in mammalian cells. Proc. Natl. Acad. Sci. 110, 2169 LP - 2174.

Martin, M. (2011). Cutadapt removes adapter sequences from high-throughput sequencing reads. EMBnet.Journal; Vol 17, No 1 Next Gener. Seq. Data Anal.

McCarthy, D.J., Campbell, K.R., Lun, A.T.L., and Wills, Q.F. (2017). Scater: Pre-

processing, quality control, normalization and visualization of single-cell RNA-seq data in R.

Bioinformatics.

De Micheli, A.J., Laurilliard, E.J., Heinke, C.L., Ravichandran, H., Fraczek, P., SoueidBaumgarten, S., De Vlaminck, I., Elemento, O., and Cosgrove, B.D. (2020). Single-Cell Analysis of the Muscle Stem Cell Hierarchy Identifies Heterotypic Communication Signals Involved in Skeletal Muscle Regeneration. Cell Rep.

Mourikis, P., and Tajbakhsh, S. (2014). Distinct contextual roles for Notch signalling in skeletal muscle stem cells. BMC Dev Biol.

Murphy, M., and Kardon, G. (2011). Origin of vertebrate limb muscle: the role of progenitor and myoblast populations. Curr Top Dev Biol 96, 1-32.

Murtaugh, L.C., Stanger, B.Z., Kwan, K.M., and Melton, D.A. (2003). Notch signaling controls multiple steps of pancreatic differentiation. Proc Natl Acad Sci U S A 100, 1492014925.

O’Flanagan, C.H., Campbell, K.R., Zhang, A.W., Kabeer, F., Lim, J.L.P., Biele, J., Eirew, P., Lai, D., McPherson, A., Kong, E., et al. (2019). Dissociation of solid tumor tissues with cold active protease for single-cell RNA-seq minimizes conserved collagenase-associated stress responses. Genome Biol.

Porrello, E.R., Mahmoud, A.I., Simpson, E., Hill, J.A., Richardson, J.A., Olson, E.N., and Sadek, H.A. (2011). Transient regenerative potential of the neonatal mouse heart. Science (80-.).

Qiu, X., Mao, Q., Tang, Y., Wang, L., Chawla, R., Pliner, H.A., and Trapnell, C. (2017).

Reversed graph embedding resolves complex single-cell trajectories. Nat. Methods. Rathore, R., McCallum, J.E., Varghese, E., Florea, A.M., and Büsselberg, D. (2017). Overcoming chemotherapy drug resistance by targeting inhibitors of apoptosis proteins (IAPs). Apoptosis.

Riehle, K.J., Dan, Y.Y., Campbell, J.S., and Fausto, N. (2011). New concepts in liver 
regeneration. J. Gastroenterol. Hepatol.

Rodriques, S.G., Stickels, R.R., Goeva, A., Martin, C.A., Murray, E., Vanderburg, C.R., Welch, J., Chen, L.M., Chen, F., and Macosko, E.Z. (2019). Slide-seq: A scalable technology for measuring genome-wide expression at high spatial resolution. Science (80-. ).

Saelens, W., Cannoodt, R., Todorov, H., and Saeys, Y. (2019). A comparison of single-cell trajectory inference methods. Nat. Biotechnol.

Sambasivan, R., Gayraud-Morel, B., Dumas, G., Cimper, C., Paisant, S., Kelly, R., and Tajbakhsh, S. (2009). Distinct Regulatory Cascades Govern Extraocular and Pharyngeal Arch Muscle Progenitor Cell Fates. Dev. Cell.

Dos Santos, M., Backer, S., Saintpierre, B., Izac, B., Andrieu, M., Letourneur, F., Relaix, F., Sotiropoulos, A., and Maire, P. (2020). Single-nucleus RNA-seq and FISH identify coordinated transcriptional activity in mammalian myofibers. Nat. Commun.

Schaum, N., Karkanias, J., Neff, N.F., May, A.P., Quake, S.R., Wyss-Coray, T., Darmanis, S., Batson, J., Botvinnik, O., Chen, M.B., et al. (2018). Single-cell transcriptomics of 20 mouse organs creates a Tabula Muris. Nature 562, 367-372.

Schuller, A.P., Wu, C.C.-C., Dever, T.E., Buskirk, A.R., and Green, R. (2017). eIF5A Functions Globally in Translation Elongation and Termination. Mol. Cell 66, 194-205.e5. Seale, P., Sabourin, L.A., Girgis-Gabardo, A., Mansouri, A., Gruss, P., and Rudnicki, M.A. (2000). Pax7 is required for the specification of myogenic satellite cells. Cell 102, 777-786. Street, K., Risso, D., Fletcher, R.B., Das, D., Ngai, J., Yosef, N., Purdom, E., and Dudoit, S. (2018). Slingshot: Cell lineage and pseudotime inference for single-cell transcriptomics. BMC Genomics.

Stuart, T., Butler, A., Hoffman, P., Hafemeister, C., Papalexi, E., Mauck III, W.M., Hao, Y., Stoeckius, M., Smibert, P., and Satija, R. (2019). Comprehensive Integration of Single-Cell Data. Cell 177, 1888-1902.e21.

Teixeira-Clerc, F., Belot, M.P., Manin, S., Deveaux, V., Cadoudal, T., Chobert, M.N., Louvet, A., Zimmer, A., Tordjmann, T., Mallat, A., et al. (2010). Beneficial paracrine effects of cannabinoid receptor 2 on liver injury and regeneration. Hepatology.

Thomsen, E.R., Mich, J.K., Yao, Z., Hodge, R.D., Doyle, A.M., Jang, S., Shehata, S.I., Nelson, A.M., Shapovalova, N. V, Levi, B.P., et al. (2016). Fixed single-cell transcriptomic characterization of human radial glial diversity. Nat Methods 13, 87-93.

Van Meeteren, L.A., and Ten Dijke, P. (2012). Regulation of endothelial cell plasticity by TGF- $\beta$. Cell Tissue Res. 347(1): 177-186.

van Velthoven, C.T.J., de Morree, A., Egner, I.M., Brett, J.O., and Rando, T.A. (2017). 
Transcriptional Profiling of Quiescent Muscle Stem Cells In Vivo. Cell Rep. 21, 1994-2004.

Wang, G., Zhu, H., Situ, C., Han, L., Yu, Y., Cheung, T.H., Liu, K., and Wu, Z. (2018).

p1 $10 \alpha$ of PI3K is necessary and sufficient for quiescence exit in adult muscle satellite cells.

EMBO J. 37, e98239.

Wang, G., Moffitt, J.R., and Zhuang, X. (2018). Multiplexed imaging of high-density libraries of RNAs with MERFISH and expansion microscopy. Sci. Rep. 8, 4847.

Wu, H., Kirita, Y., Donnelly, E.L., and Humphreys, B.D. (2019). Advantages of Single-

Nucleus over Single-Cell RNA Sequencing of Adult Kidney: Rare Cell Types and Novel Cell

States Revealed in Fibrosis. 23-32.

Wu, Y.E., Pan, L., Zuo, Y., Li, X., and Hong, W. (2017). Detecting Activated Cell

Populations Using Single-Cell RNA-Seq. Neuron 96, 313-329.e6.

Yamaguchi, M., Watanabe, Y., Ohtani, T., Uezumi, A., Mikami, N., Nakamura, M., Sato, T., Ikawa, M., Hoshino, M., Tsuchida, K., et al. (2015). Calcitonin Receptor Signaling Inhibits Muscle Stem Cells from Escaping the Quiescent State and the Niche. Cell Rep 13, 302-314. Yates, A., Akanni, W., Amode, M.R., Barrell, D., Billis, K., Carvalho-Silva, D., Cummins, C., Clapham, P., Fitzgerald, S., Gil, L., et al. (2016). Ensembl 2016. Nucleic Acids Res. 


\begin{tabular}{|c|c|c|}
\hline REAGENT or RESOURCE & SOURCE & IDENTIFIER \\
\hline \multicolumn{3}{|l|}{ Antibodies } \\
\hline Anti-ERK1/2 rabbit polyclonal & EMD Millipore & $06-182$ \\
\hline Anti-phospho-ERK1/2 mouse & Abcam & ab50011 \\
\hline Anti-phospho-ERK1/2 rabbit & Cell signaling Technology & 9101 \\
\hline anti-rabbit & Vector Laboratories & PI-1000 ZD0821 \\
\hline anti-mouse & Vector Laboratories & PI-2000-1 ZC1212 \\
\hline \multicolumn{3}{|l|}{ Bacterial and Virus Strains } \\
\hline & & \\
\hline & & \\
\hline & & \\
\hline \multicolumn{3}{|l|}{ Biological Samples } \\
\hline & & \\
\hline & & \\
\hline & & \\
\hline \multicolumn{3}{|c|}{ Chemicals, Peptides, and Recombinant Proteins } \\
\hline Matrigel & Corning & 354248 \\
\hline DMEM & Gibco & $41966-029$ \\
\hline \multicolumn{3}{|l|}{ FBS } \\
\hline bFGF & Peprotech & $450-33$ \\
\hline ERK inhibitor SCH772984 & Selleckchem & S7101 \\
\hline ODC1 inhibitor DFMO & Tocris & 2761 \\
\hline Ketamine and xylazine & VMD & \\
\hline $\mathrm{BaCl} 2$ & Sigma & 202738 \\
\hline $\mathrm{CCl} 4$ & Sigma & 289116 \\
\hline RNase inhibitor & Roche & 03335399001 \\
\hline BSA & Jackson Laboratories & $001-000-162$ \\
\hline phosSTOP & Merck & 4906845001 \\
\hline Collagenase A $1 \mathrm{U} / \mathrm{ml}$ & Roche & 10103586001 \\
\hline Dispase II & Roche & 4942078001 \\
\hline PKD buffer & Qiagen & 1034963 \\
\hline proteinase $\mathrm{K}$ & Qiagen & 19131 \\
\hline \multicolumn{3}{|l|}{ Critical Commercial Assays } \\
\hline EdU Click-iT PLUS Kit & Life Technologies & C10640 \\
\hline Bolt $^{\mathrm{TM}} 4-12 \%$ Bis-Tris Plus Gels & Thermofisher & NW04120BOX \\
\hline $\begin{array}{l}\text { the iBlot }{ }^{\top M} 2 \text { Transfer Stacks, PVDF, } \\
\text { mini kit }\end{array}$ & Thermofisher & IB24002 \\
\hline $\begin{array}{l}\text { SuperSignal }{ }^{\mathrm{TM}} \text { West Femto Maximum } \\
\text { Sensitivity Substrate }\end{array}$ & Thermofisher & 34094 \\
\hline Quick RNA FFPE kit & Zymo & R1008 \\
\hline
\end{tabular}




\begin{tabular}{|c|c|c|}
\hline RecoverAll FFPE kit & Thermofisher & AM1975 \\
\hline SuperScript IV VILO Master Mix & Thermofisher & 11756050 \\
\hline Power SYBR Green PCR Master Mix & Applied Biosystems & 4367659 \\
\hline Chromium Single Cell 3' Reagent Kits & 10x Genomics & 1000074 \\
\hline DynaBeads MyOne Silane Beads & Thermofisher & 37002D \\
\hline SPRIselect Reagent Kit & Beckman & C10640 \\
\hline High Sensitivity ${ }^{T M}$ HS DNA kit & Agilent & $5067-4626$ \\
\hline $\begin{array}{l}\text { Qubit }{ }^{T M} \text { dsDNA High Sensitivity HS } \\
\text { assay }\end{array}$ & Thermofisher & Q32851 \\
\hline $\begin{array}{l}\text { Smarter Stranded Total RNA-Seq kit- } \\
\text { Pico Input Mammalian }\end{array}$ & Clontech & 635005 \\
\hline Illumina HiSeq SR Cluster Kit v4 & Illumina & GD-401-4001 \\
\hline KAPA HIFI Hot Start ReadyMix & Roche & 07958919001 \\
\hline quantifluor RNA system & Promega & E3310 \\
\hline Nextera XT library prep and index kit & Illumina & $\begin{array}{l}\text { FC-131-1096 and FC- } \\
131-2001\end{array}$ \\
\hline \multicolumn{3}{|l|}{ Deposited Data } \\
\hline \multicolumn{3}{|l|}{ GEO accession number GSE163856 } \\
\hline \multicolumn{3}{|l|}{ Experimental Models: Cell Lines } \\
\hline \multicolumn{3}{|c|}{ Experimental Models: Organisms/Strains } \\
\hline Tg:Pax7-nGFP & Jackson Laboratories & MGI:5308730 \\
\hline$R 26 R^{\text {stop-NICD-nGFP }}$ & Jackson Laboratories & stock 008159 \\
\hline Pax7-CreERT2 & Jackson Laboratories & stock 017763 \\
\hline \multicolumn{3}{|l|}{ Oligonucleotides } \\
\hline \multicolumn{3}{|l|}{$\begin{array}{l}\text { Sequence of RT-qPCR primers } \\
\text { are listed in Table S3 }\end{array}$} \\
\hline \multicolumn{3}{|l|}{ Recombinant DNA } \\
\hline & & \\
\hline & & \\
\hline & & \\
\hline
\end{tabular}




\begin{tabular}{|l|l|l|}
\hline \multicolumn{2}{|l|}{} & \\
\hline Software and Algorithms & & \\
\hline Illumina Pipeline software & Casava & version 1.9 \\
\hline $\begin{array}{l}\text { Cell Ranger Single Cell Software } \\
\text { Suite }\end{array}$ & 10X Genomics & version 3.0.2 \\
\hline STAR & (Dobin et al., 2013) & version 2.4.0, 2.5.0a \\
\hline R & R core team & version 3.4.3 \& 3.5.1 \\
\hline Seurat & (Stuart et al., 2019) & version 3.0.2 \\
\hline TabulaMuris R package & (Schaum et al., 2018) & version 1.0 \\
\hline Sequana RNA-seq pipeline & (Cokelaer et al., 2017) & Version 0.9.19 \\
\hline cutadapt & (Martin, 2011) & version 1.11 \& 1.5 \\
\hline featureCounts & (Liao et al.., 2013) & version 1.4.6-p3 \\
\hline DESeq2 & (Love et al., 2014) & version 1.18.1 \\
\hline htseq-count & (Anders et al., 2015) & version 0.6.0 \\
\hline Scater & (McCarthy et al., 2017) & version 1.8.4 \\
\hline Scran & (Lun et al., 2016) & version 1.8.4 \\
\hline Python & Python software & version 3.6 \\
& foundation & \\
\hline MAST & (Finak et al., 2015) & version 1.10 \\
\hline Monocle2 & (Qiu et al., 2017) & version 2.12.0 \\
\hline Slingshot & (Street et al., 2018) & version 1.4 \\
\hline & & \\
\hline & & \\
\hline & & \\
\hline & & \\
\hline Other & & \\
\hline & & \\
\hline & & \\
\hline & & \\
\hline & & \\
\hline & & \\
\hline & & \\
\hline & & \\
\hline & & \\
\hline & & \\
\hline
\end{tabular}


Figure 1 Machado et al., 2020

A

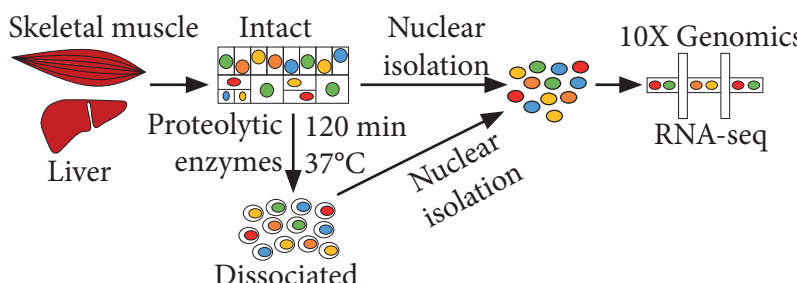

C

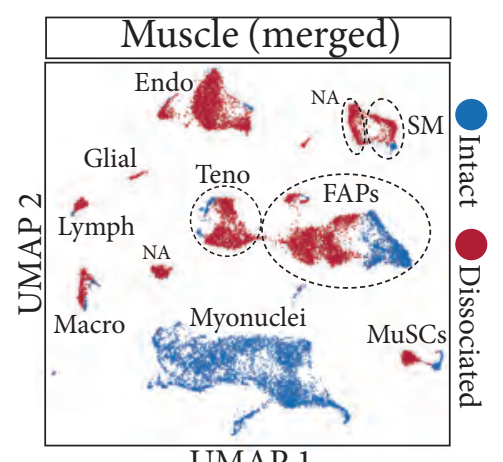

UMAP 1

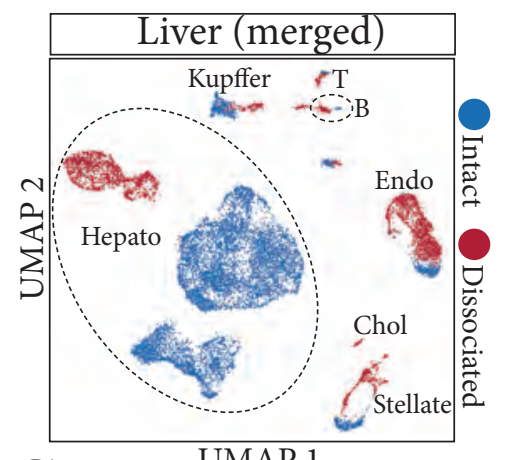

G

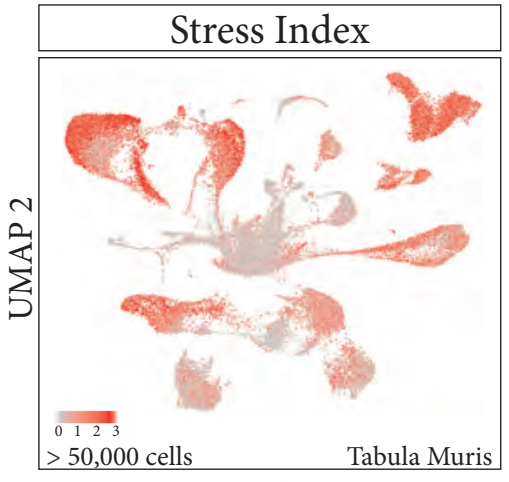

UMAP 1
D

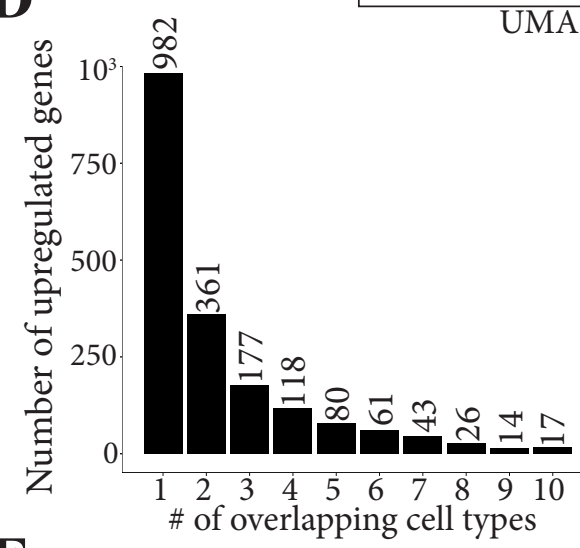

$\mathbf{E}$

Stress core (98 genes)

\begin{tabular}{|l|l|l|}
\hline Atf3 & Hsp90ab1 & Ubc \\
\hline Junb & Hspa8 & Klf6 \\
\hline Fos & Klf4 & Lmna \\
\hline Azin1 & Erf & Gm48099 \\
\hline Jund & Egr1 & Cdkn1a \\
\hline Fosb & Gls & Hsp90aa1 \\
\hline Fos12 & Zfp36 & Elf2 \\
\hline Jun & Jak1 & Stat3 \\
\hline
\end{tabular}

H

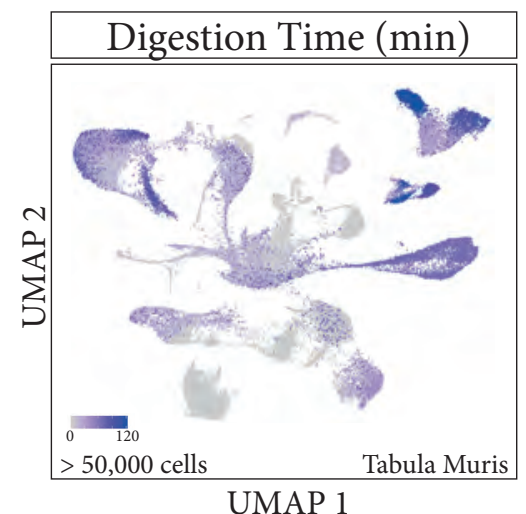

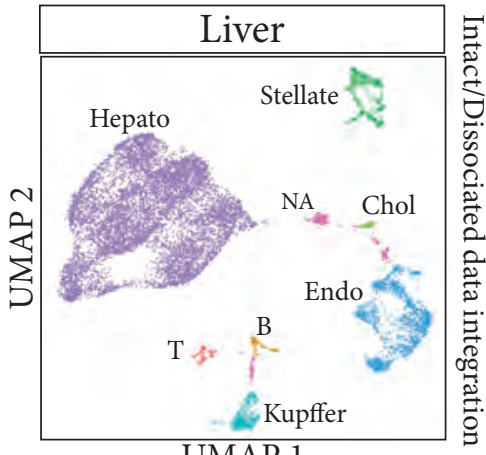

UMAP 1

$\mathbf{F}$

Gene Ontology

P38MAPK cascade

Transcription from RNA polymerase II promoter in response to stress

Adherens junction assembly

Transcription by RNA polymerase II

Stress-activated MAPK cascade

Response to mechanical stimulus

Cellular response to growth factor stimulus

Response to growth factor

Positive regulation of cell-cell adhesion

Response to cytokine

Positive regulation of cell migration

Inflammatory response

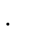

$\begin{array}{lllll}0 & 5 & 10 & 20 & 50\end{array}$

Fold-change dissociated/intact

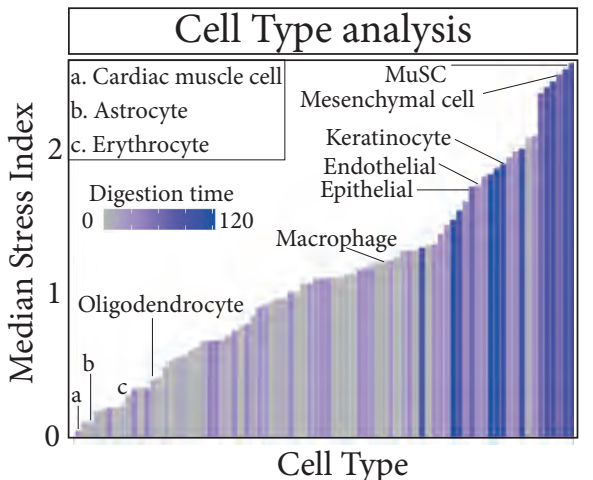


Figure 2 Machado et al., 2020

A

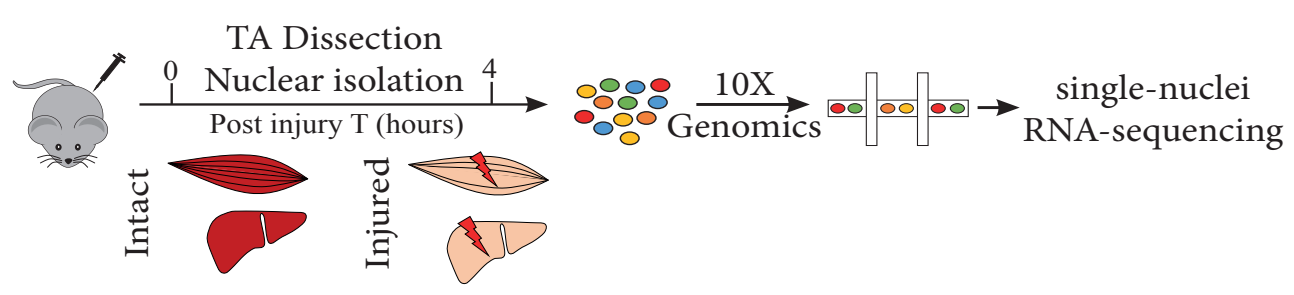

B

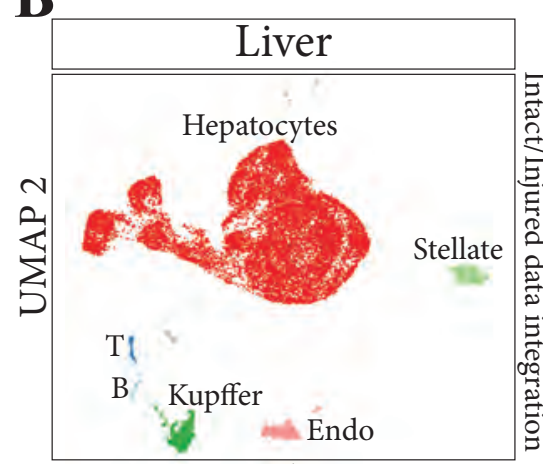

UMAP 1

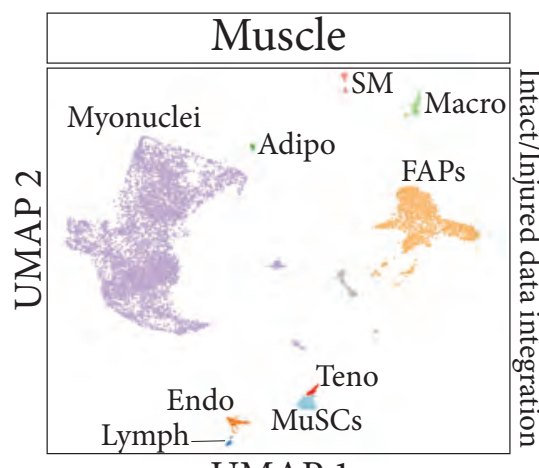

E

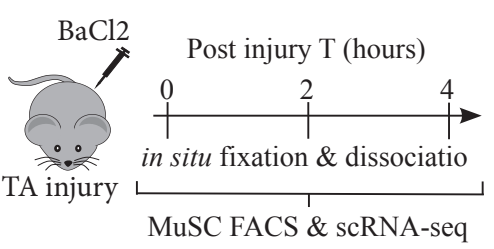

H

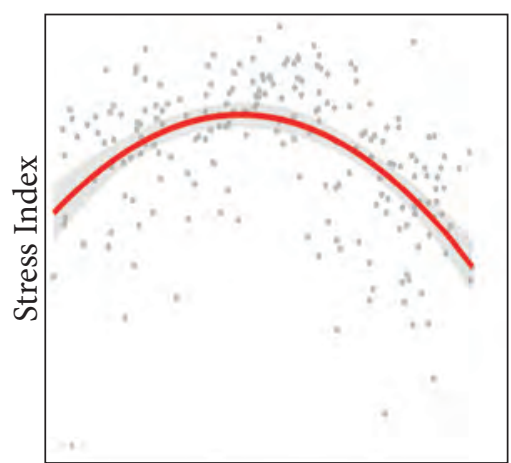

Pseudotime
C

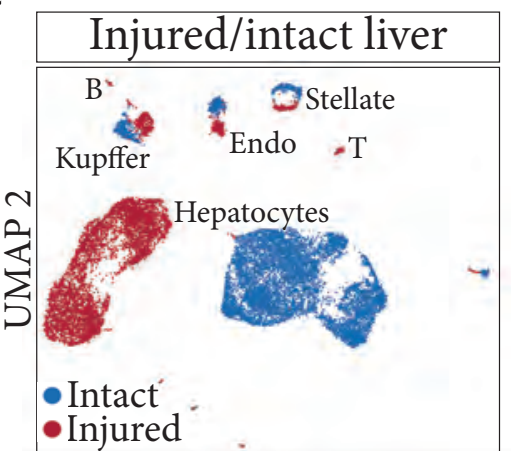
UMAP 1

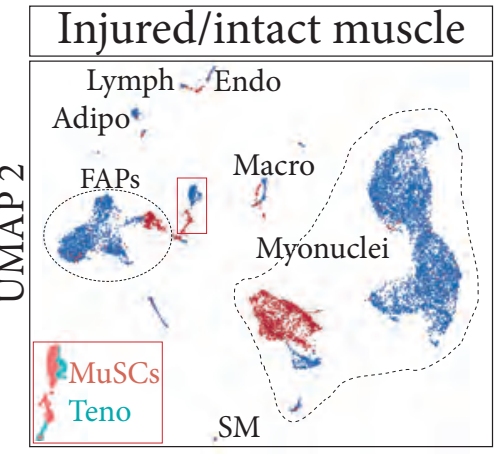

UMAP 1

F

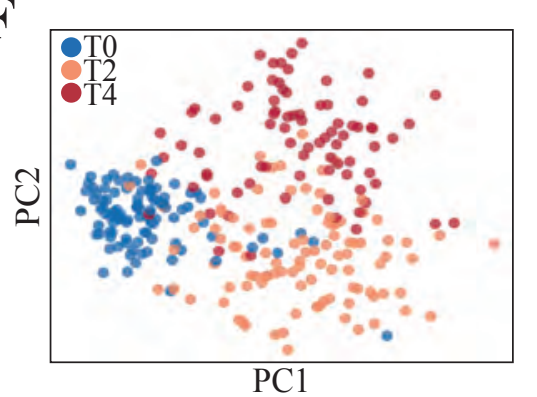

D

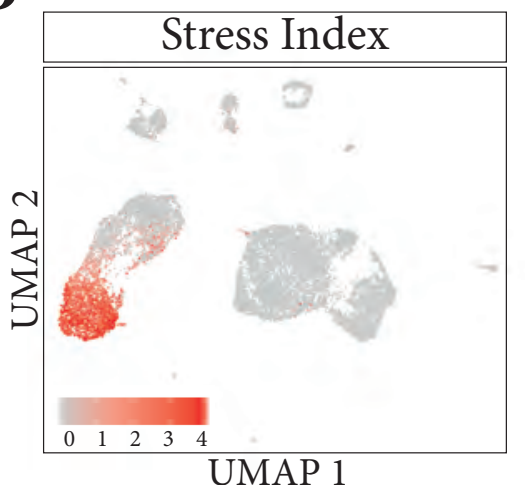

UMAP 1

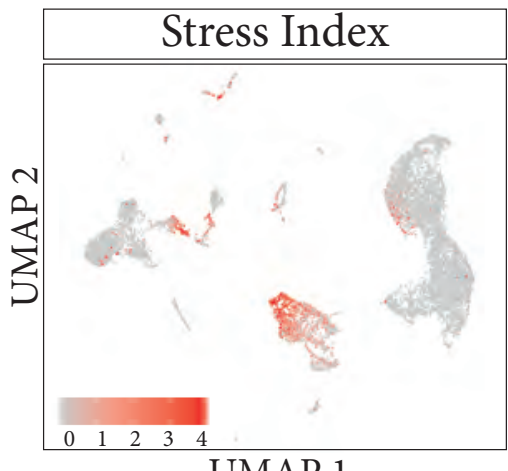

UMAP 1

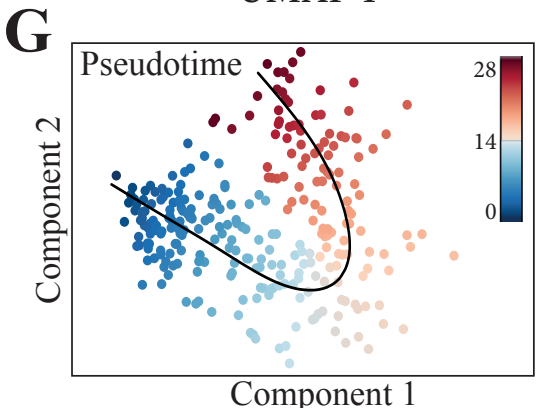


Figure 3 Machado et al., 2020

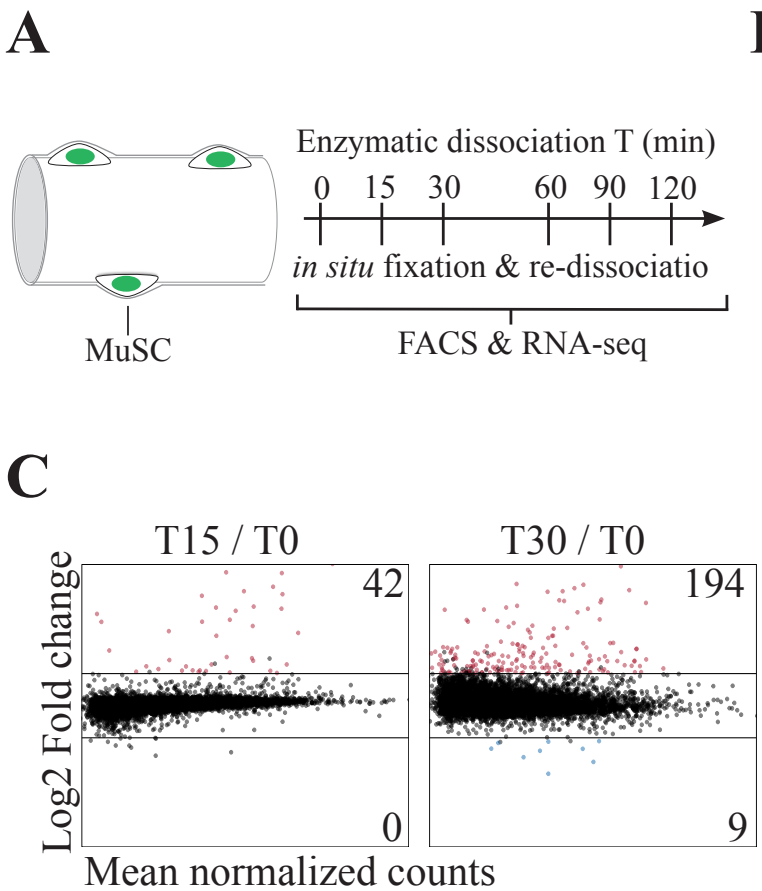

D Cluster

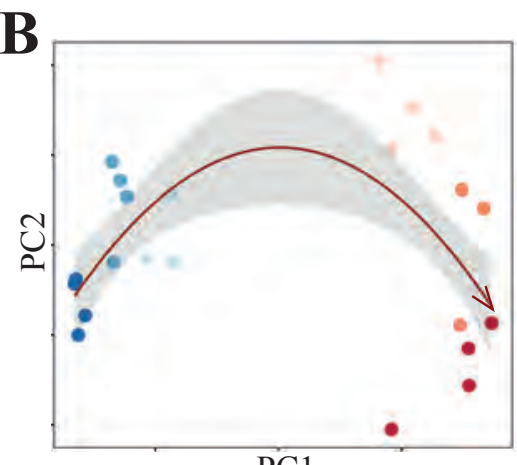

PC1

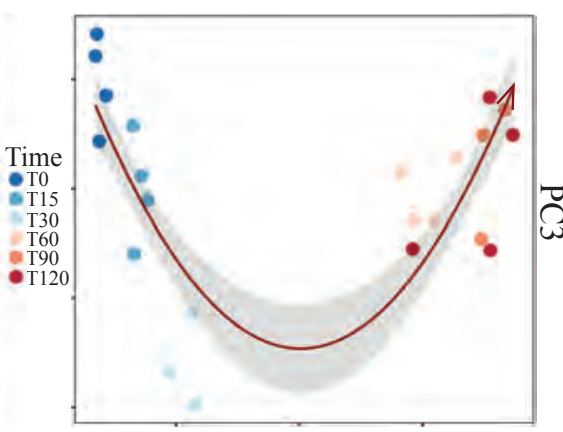

PC1
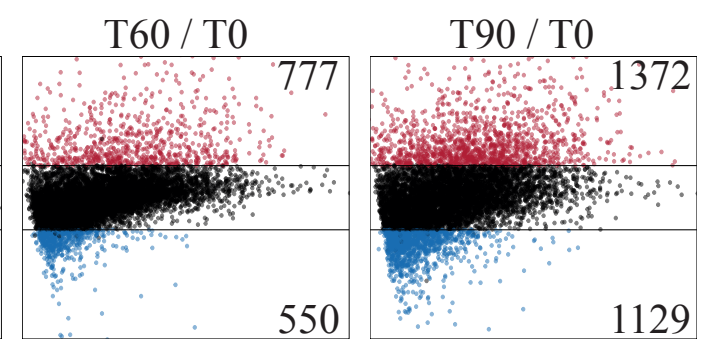

T120 / T0

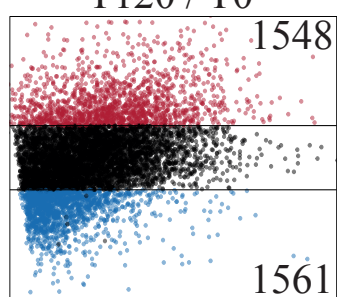

1561

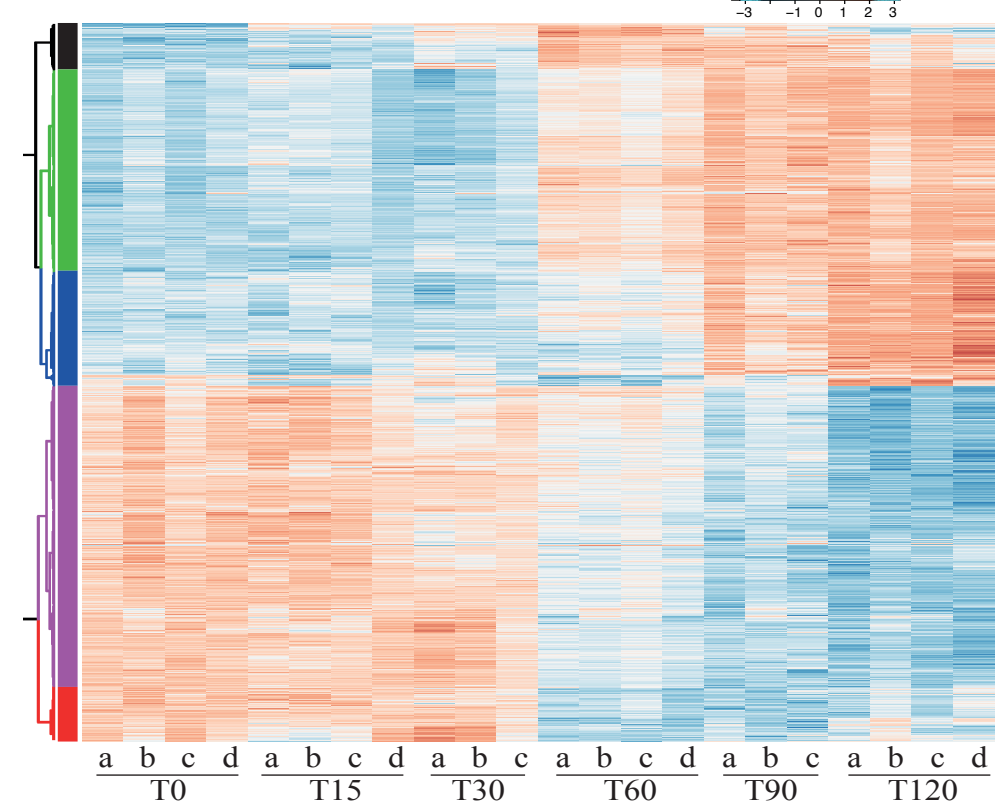

$\mathbf{E}$

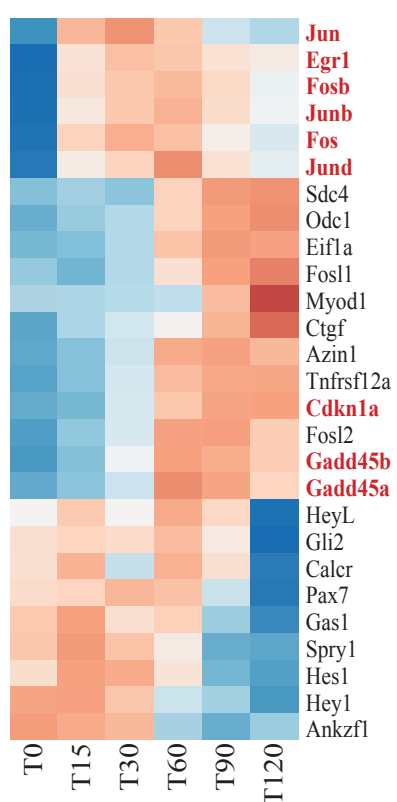

F

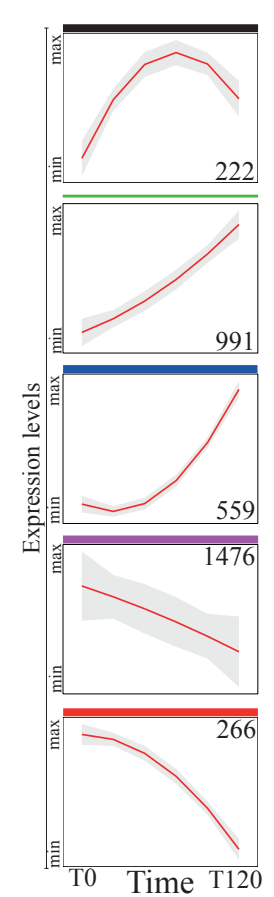

G

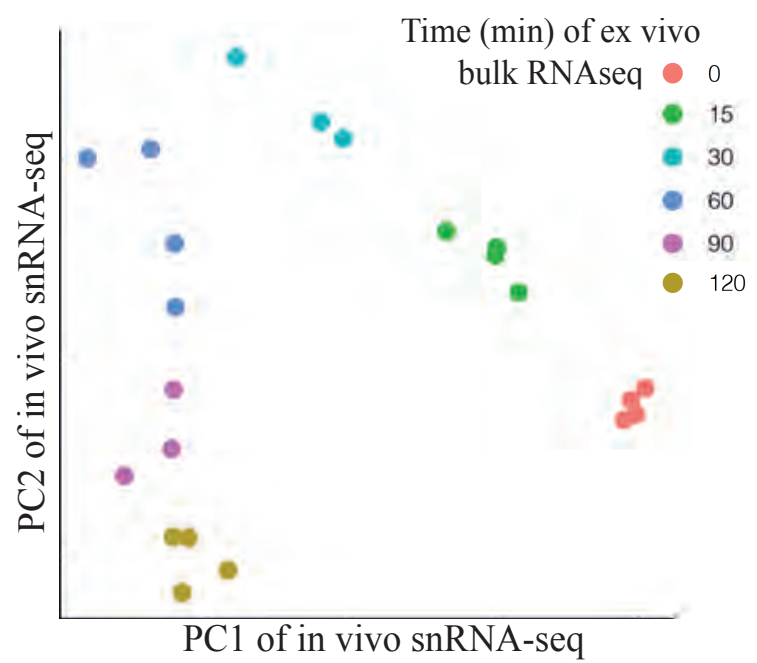

H

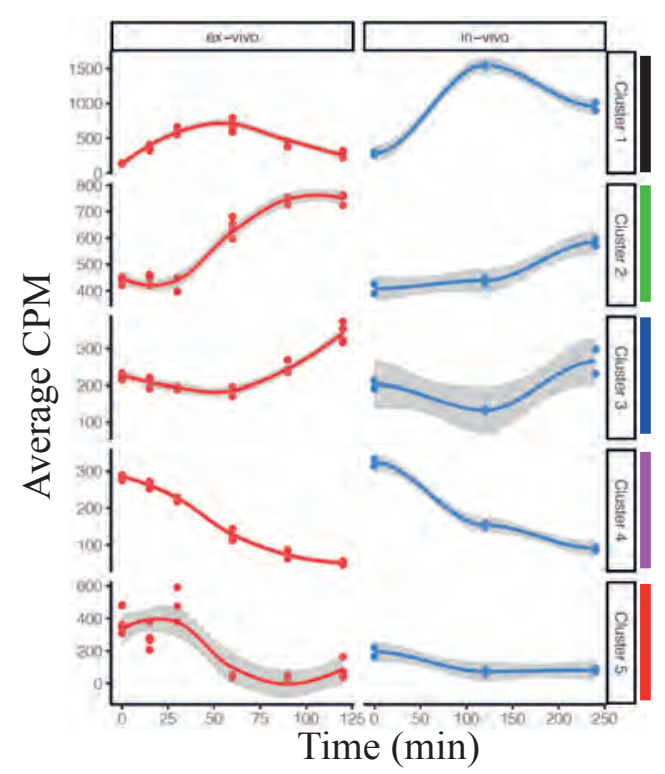


Figure 4 Machado et al., 2020

A
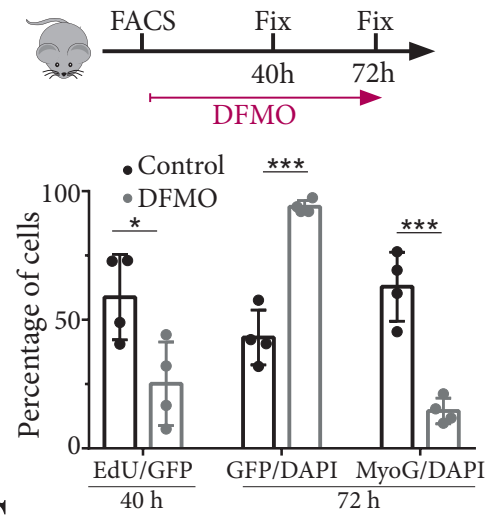

C
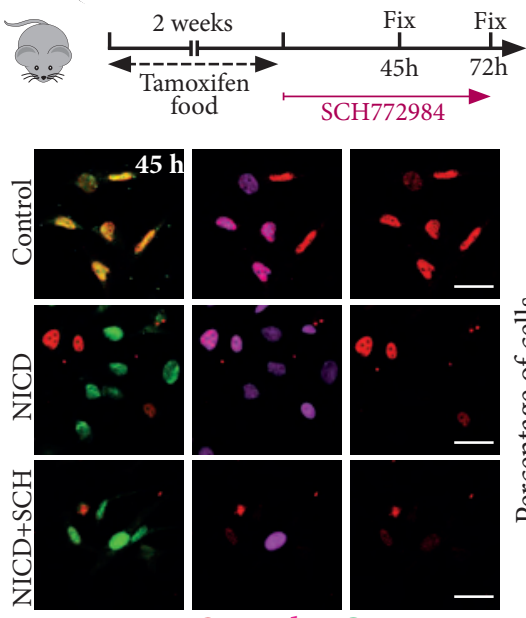

MYOD EdU GFP

E

ชิ

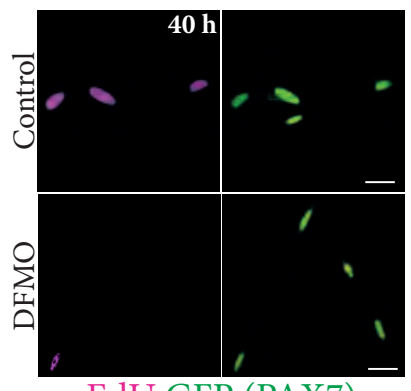

EdU GFP (PAX7)

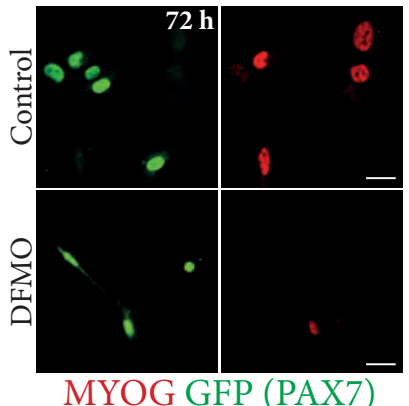

MYOG GFP (PAX7)

\section{D}
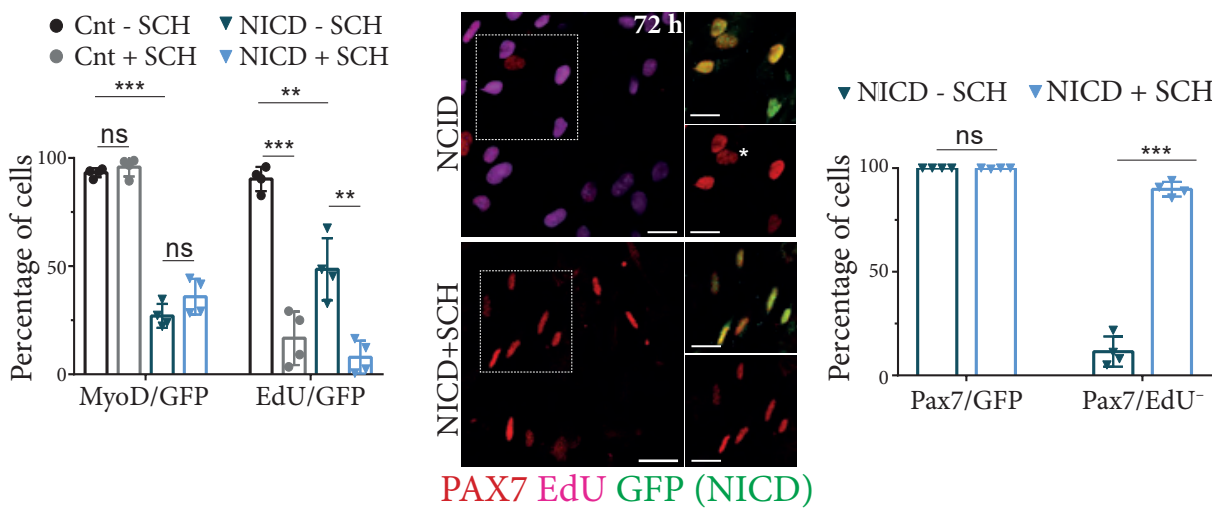

F

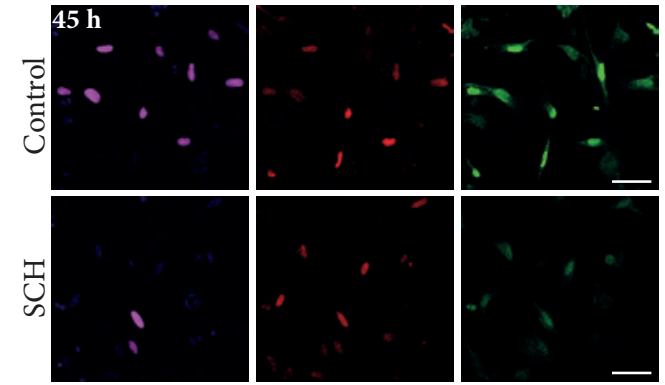

MYOD EdU GFP (PAX7)

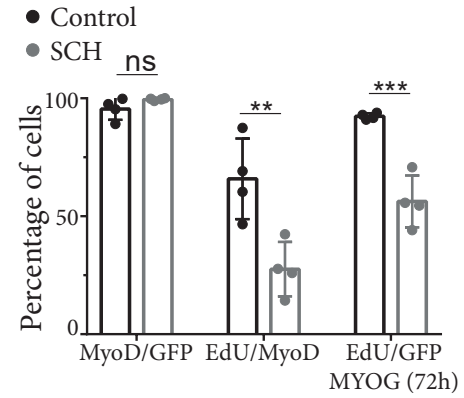


Figure S1 Machado et al., 2020

A Digested Liver Intact Liver

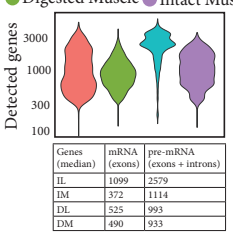

C

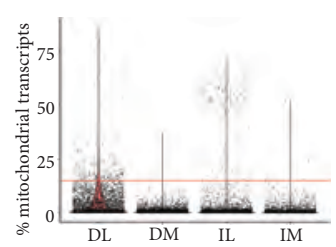

G

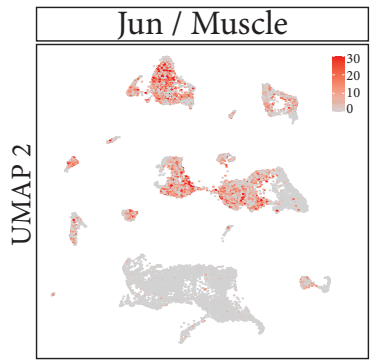

UMAP 1
B

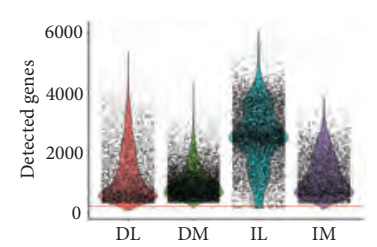

D
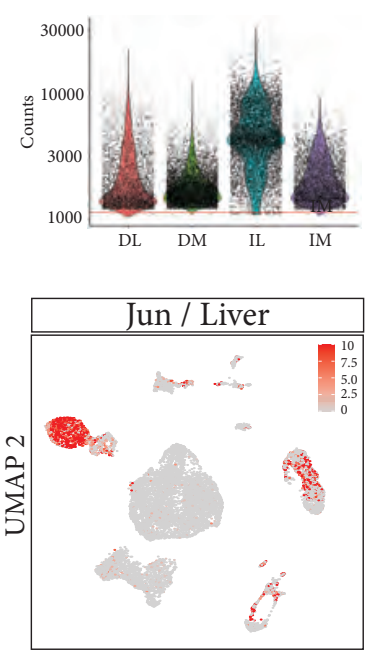

$\mathbf{E}$

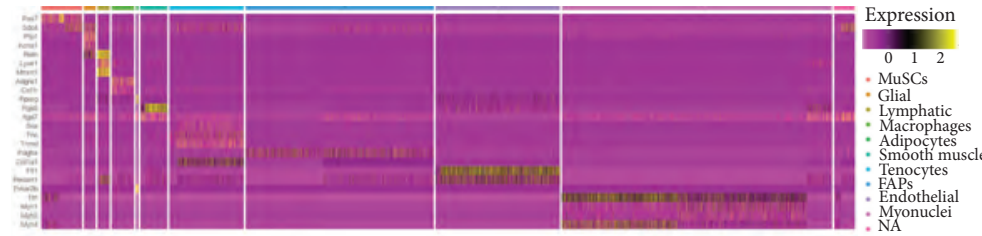

F

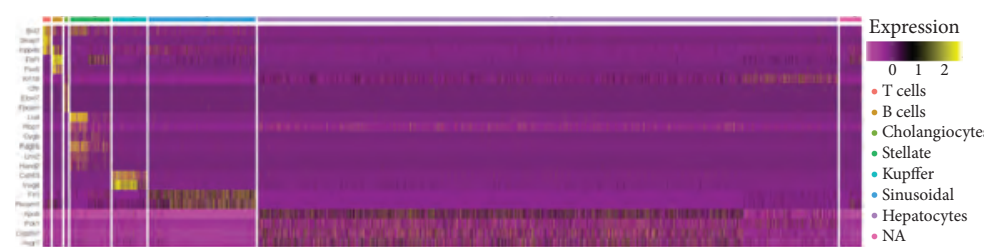

H

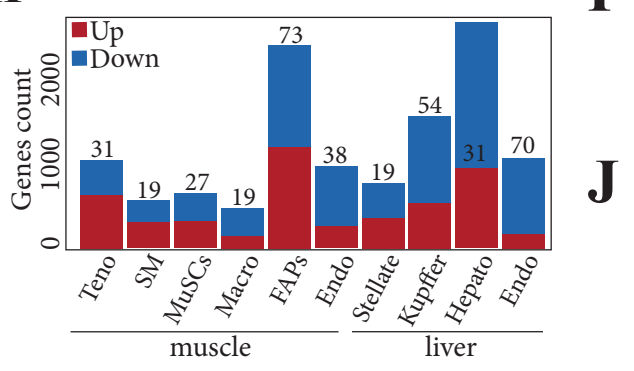

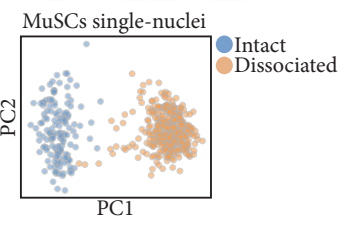

MuSCs DEGs

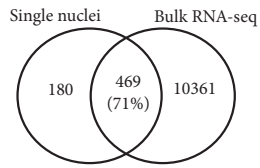

K
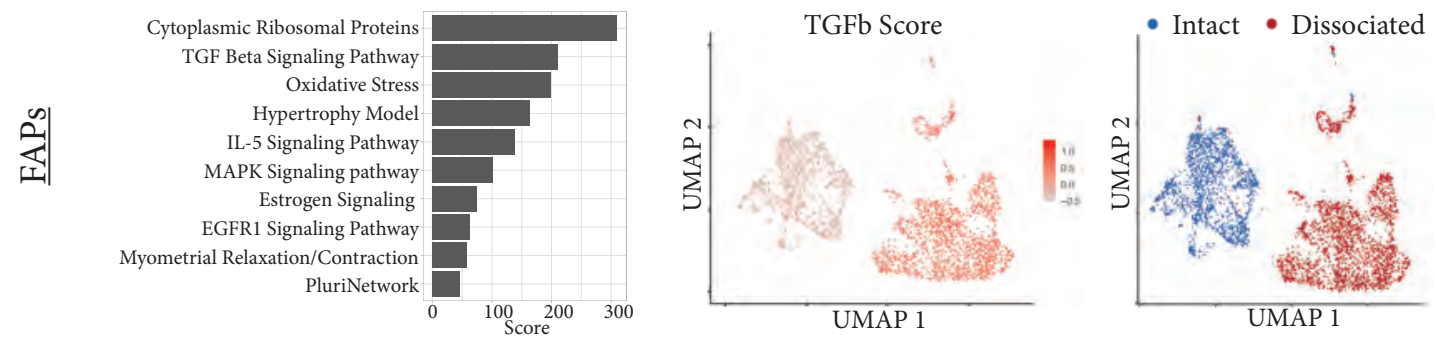

L
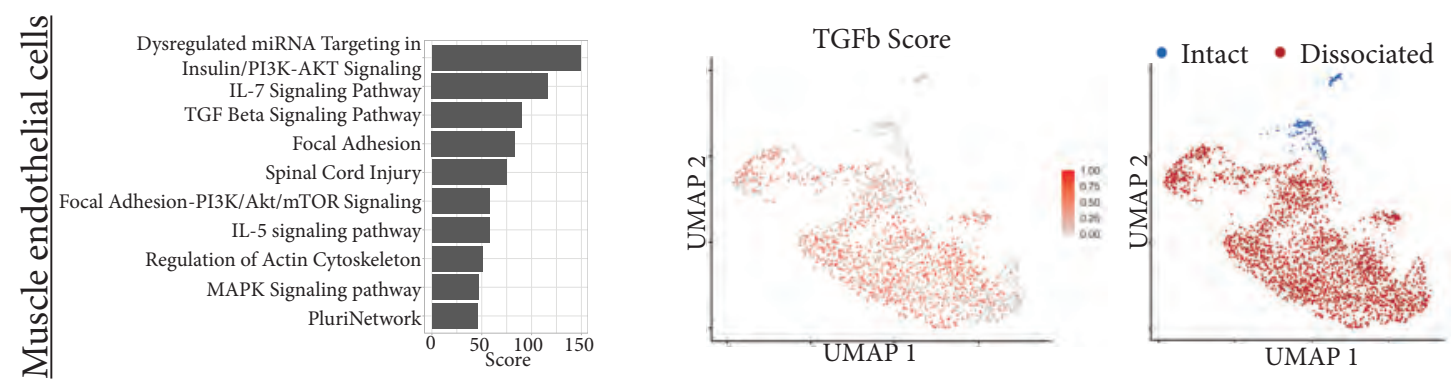

M

包
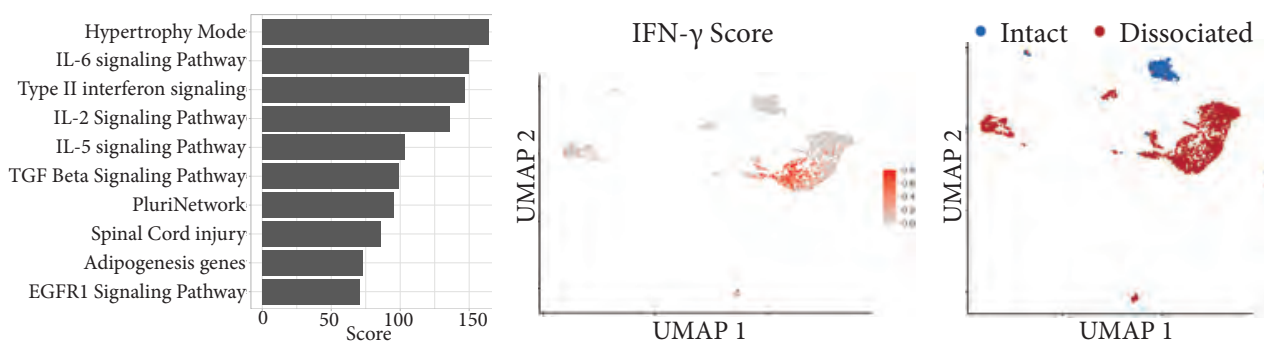

$\mathbf{N}$
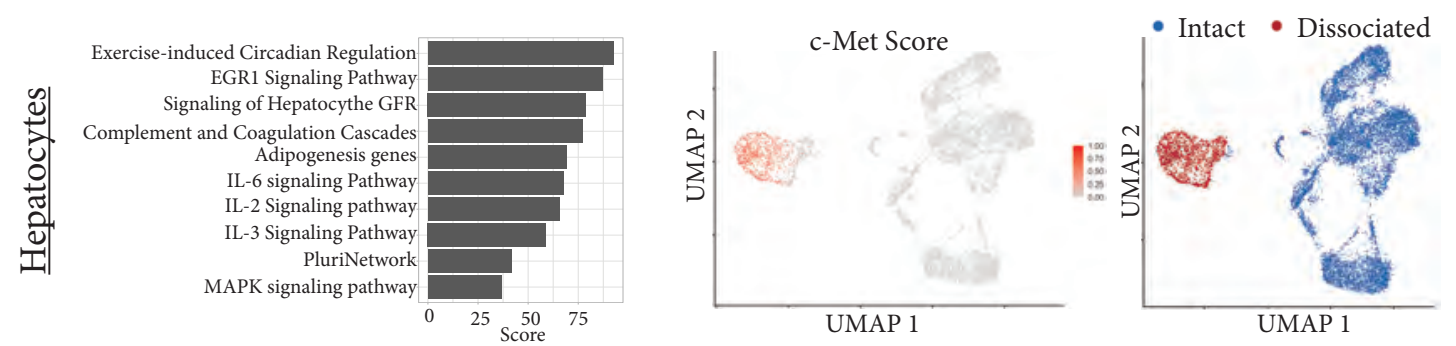
Figure S1. Cell populations and gene deregulation in intact and dissociated muscle and liver. Related to Figure 1.

(A) Violin plots of detected genes in intact and dissociated muscle and liver scRNA-seq experiments. (bottom) Table summarizing the median number of genes using mRNA (exonic sequences only) or pre-mRNA (exonic and intronic sequences).

(B) Number of detected genes per sample using pre-mRNA sequences. The red line represents the quality cutoff set at 250 .

(C) Percentage of mitochondrial genes detected per sample. The red line represents the quality cutoff set at $15 \%$.

(D) Number of reads per sample using pre-mRNA sequences. The red line represents the quality cutoff set at 500 .

(E) Heatmap displaying the expression of common cell population markers used to annotate the nuclei from integrated intact and dissociated Tibialis Anterior muscle snRNA-seq.

(F) Heatmap displaying the expression of common cell population markers used to annotate the nuclei from integrated intact and dissociated liver snRNA-seq.

(G) UMAP plots displaying the expression of a typical dissociation-response gene Jun in muscle (left) and liver (right) intact and dissociated cells (see Fig. 1C for corresponding identities).

(H) Differential gene expression in the 10 main cell populations using Seurat. Up: up-regulated by dissociation; Down: down-regulated by dissociation. On each bar the percentage of DEGs divided by the total detected genes within this population is indicated. Detected genes are those with at least one count in at least 10 percent of the cells of the population.

(I) PCA analysis of MuSCs single-nuclei isolated from intact and dissociated muscle. PC1 explain $7 \%$ of the experimental variance and PC2 $4 \%$.

(J) Venn Diagram showing the overlap between single-nucleus and bulk RNA-seq MuSCs dissociation-induced DEGs (both up- and down-regulated, adjusted p-value $<0.05$ ). The bulk RNA-seq DEGs are extracted from Machado et al., 2017.

(K-N) (left) Pathways analysis (Wikipathways_2019 vie Enrichr) displaying upregulated terms during dissociation of selected cell-types (adjusted p-value $<0.05$ and ranked by combined_score); (middle) combined expression of upregulated genes from the selected signaling pathways visualized using the Seurat AddModuleScore() function in the selected cell-types; (right) UMAPplots of the merged intact and dissociated selected cell-types. Analysis of the upregulated genes showed enrichment for cell-specific biological processes. These included TGF- $\beta$ signaling in the FAPs $(\mathrm{K})$, known to be induced in the mesenchymal stromal cells during muscle regeneration (Contreras et al., 2019). TGF- $\beta$ signaling is also involved in angiogenesis and was found enriched in muscle endothelial cells (L) (Van Meeteren and Ten Dijke, 2012). Moreover, we found a prominent response to cytokines in different cell-types with Interferon-gamma signaling in liver 
sinusoidal cells (M) and Interleukin (IL) -5 signaling highly enriched in muscle endothelial cells and FAPs, and IL-6, IL-2 (not shown). Hepatocytes were also enriched with terms for IL-6 and IL-2 in addition to c-Met signaling, a pathway that is critical for liver regeneration $(\mathrm{N})$, (Ishikawa et al., 2012).

For panels A-D: DL: Digested Liver; DM: Digested Muscle; IL: Intact Liver; IM: Intact Muscle. 
Figure S2 Machado et al., 2020

A

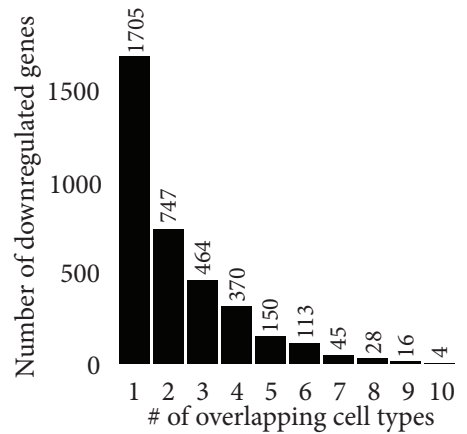

B
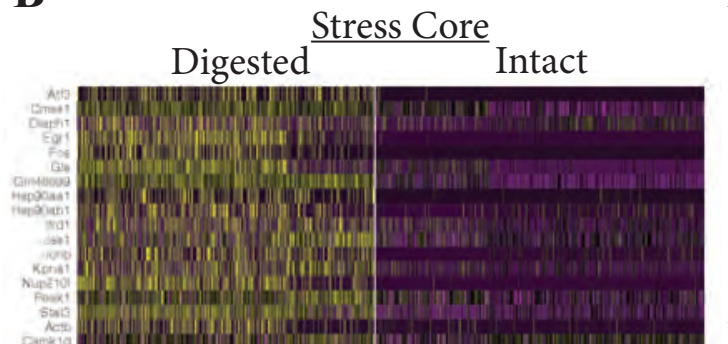

E

Dissociation time $\frac{0 \text { min }}{\mathrm{A} \quad \mathrm{C}} \quad \frac{15 \mathrm{~min}}{\mathrm{~A} B \mathrm{C}}$

pERK1/2

Total ERK1/2

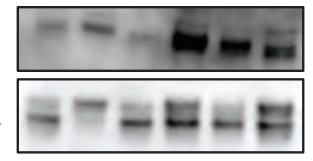

F

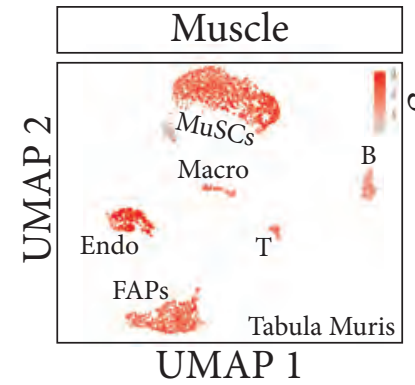

G

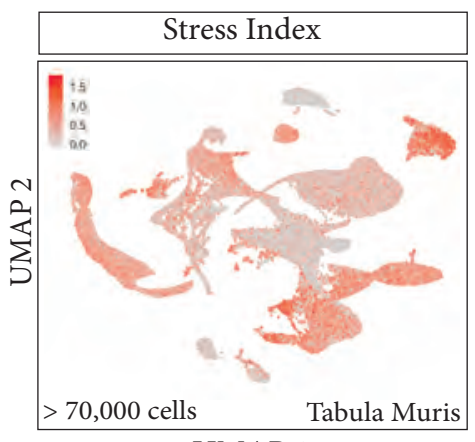

UMAP 1
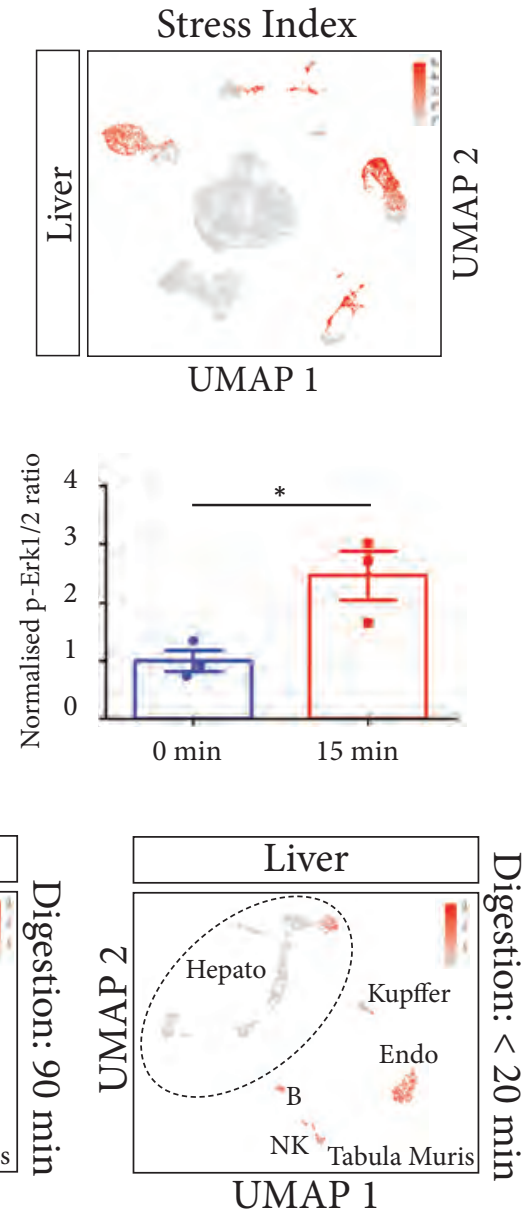

H

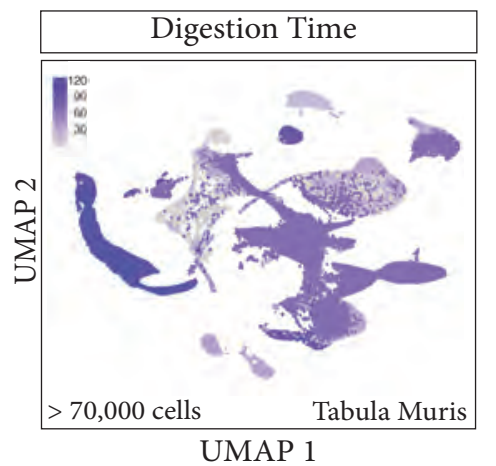

K

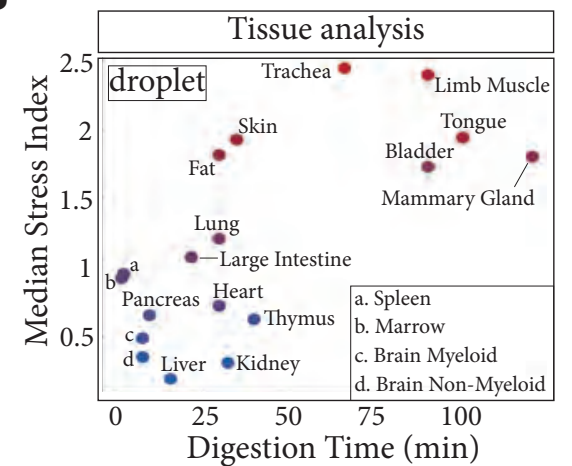

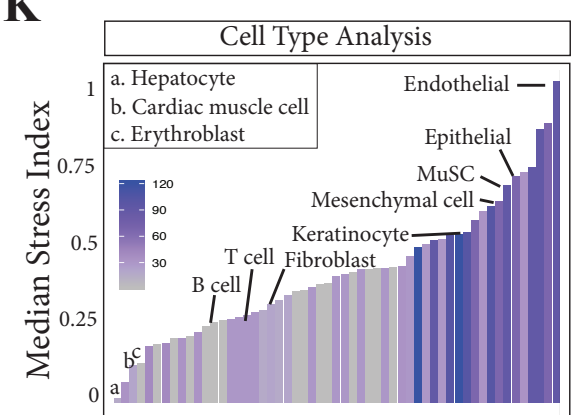

Cell Type 
Figure S2. Conserved, digestion-time dependent stress response in muscle, liver and published datasets. Related to Figure 1.

(A) Histogram representing the distribution of downregulated genes by dissociation in the 10 main populations (sinusoidal cells, hepatocytes, Kupffer cells, stellate cells, FAPs, tenocytes, muscle endothelial cells, smooth muscle cells, MuSCs, and macrophages) that we found in the muscle and liver snRNA-seq atlases (see Figure 1B).

(B) Heatmap displaying the expression of the Stress core genes in all cells from muscle and liver snRNA-seq, grouped by dissociation status (digested/intact).

(C) Stress index in UMAP plots of all cells from intact and dissociated muscle and liver (dissociation status blue/red in Fig. 1C). The Stress Index was calculated by the average expression of the 98 Stress core genes.

(D) Western blot analysis of ERK1/2 phosphorylation on intact ( 0 min) and 15 min digested whole muscle, showing early MAPK activation. (right) Quantification of pERK1 2 over total ERK ration (student t-test, $* \mathrm{p}<0.05$ ).

(E) Graphical representation of the analysis: Stress core genes were used to calculate the Stress Index into the Tabula Muris datasets using more than 120,000 cells from the droplet $(>50,000$ cells) and the Smart-Seq2 $(>70,000)$ datasets across 20 tissues.

(F) UMAP plots representing the Stress Index across 2,102 muscle single-cells (left) and 981 liver single-cells (right) from the published Tabula Muris Smart-Seq2 dataset. The digestion times at $37^{\circ} \mathrm{C}$ is indicated adjacent to the panels: $90 \mathrm{~min}$ for muscle and $<20 \mathrm{~min}$ for liver.

(G) UMAP plot representing the Stress Index of every cell from the published Tabula Muris droplet dataset $(70,118$ cells).

(H) UMAP plot representing the digestion time at $37{ }^{\circ} \mathrm{C}$ of every cell from the published Tabula Muris droplet dataset (70,118 cells). Note the correlation between digestion time and Stress Index (Spearman correlation index: 0.54).

(I) Correlation between tissue digestion time at $37{ }^{\circ} \mathrm{C}$ and median tissue Stress Index calculated from the Tabula Muris Smartseq2 dataset. Spearman correlation index: 0.71.

(J) Correlation between tissue digestion time at $37{ }^{\circ} \mathrm{C}$ and median tissue Stress Index calculated from the Tabula Muris droplet dataset. Spearman correlation index: 0.71.

(K) Median Stress Index in different cell types calculated from the Tabula Muris droplet dataset. Median cell-type digestion time at $37^{\circ} \mathrm{C}$ is color-coded (grey/blue gradient). 
Figure S3 Machado et al., 2020

A

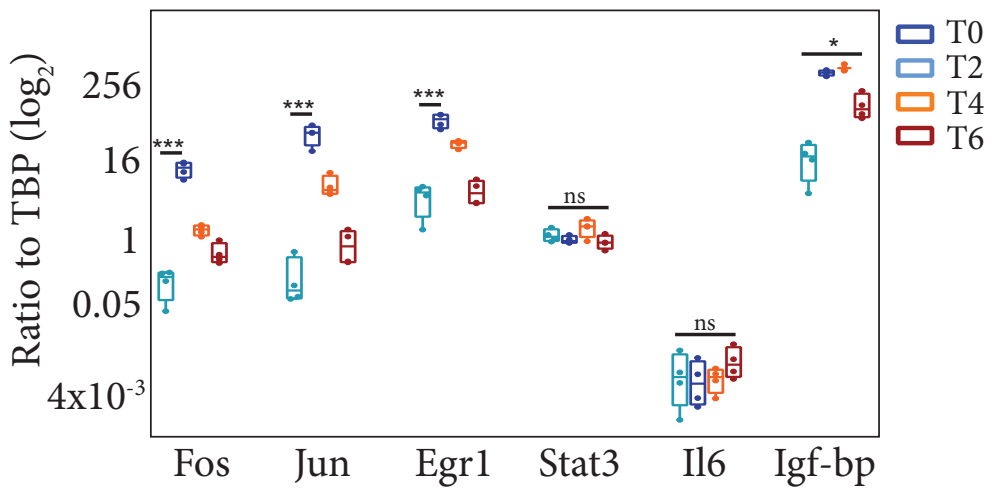

B

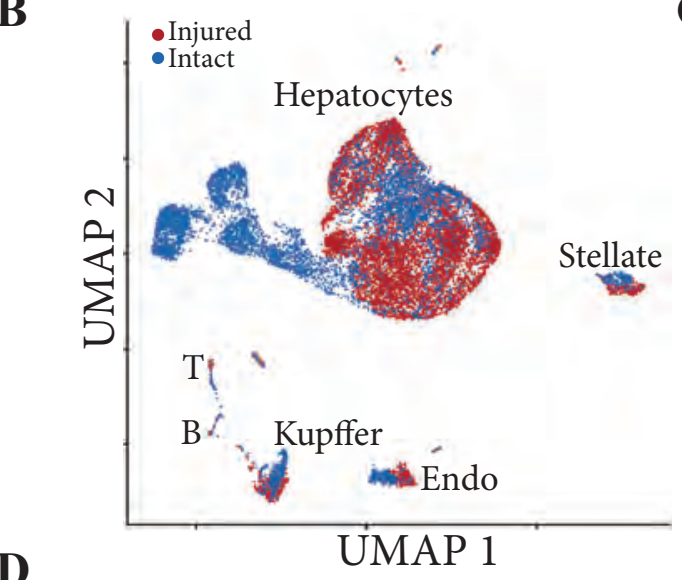

C
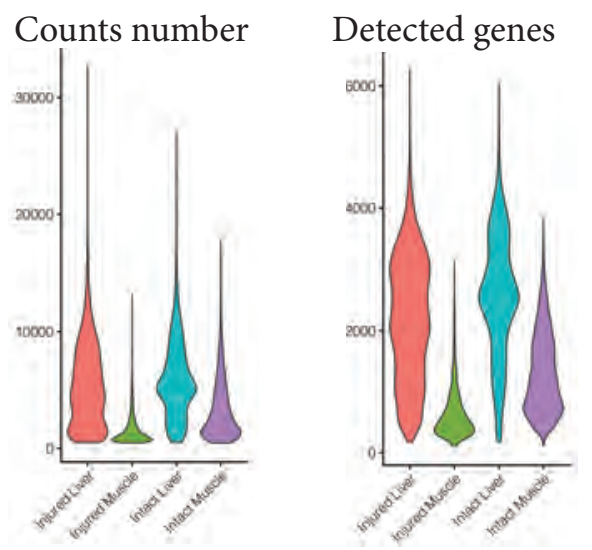

$\%$ mitochondrial genes
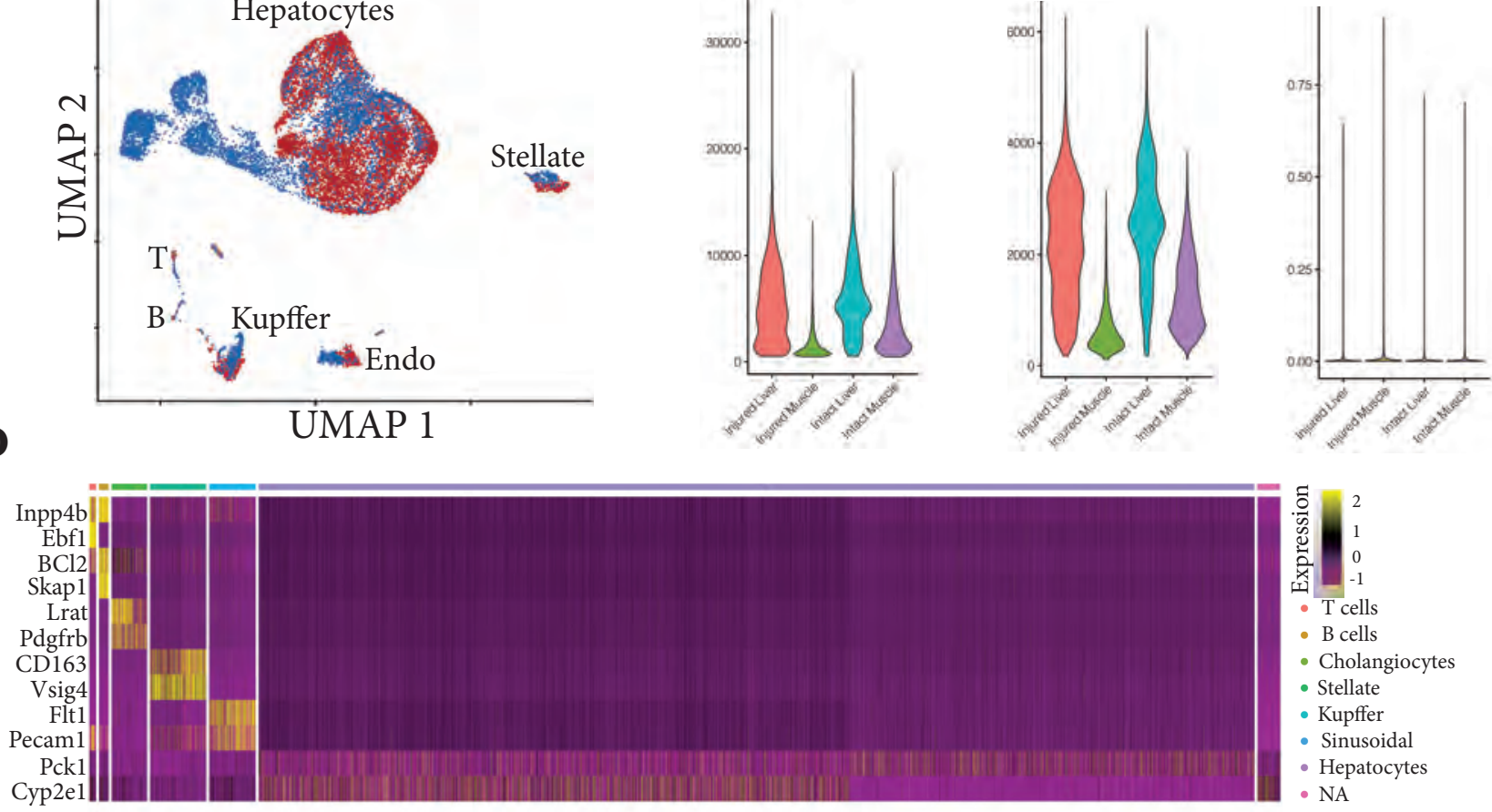

E

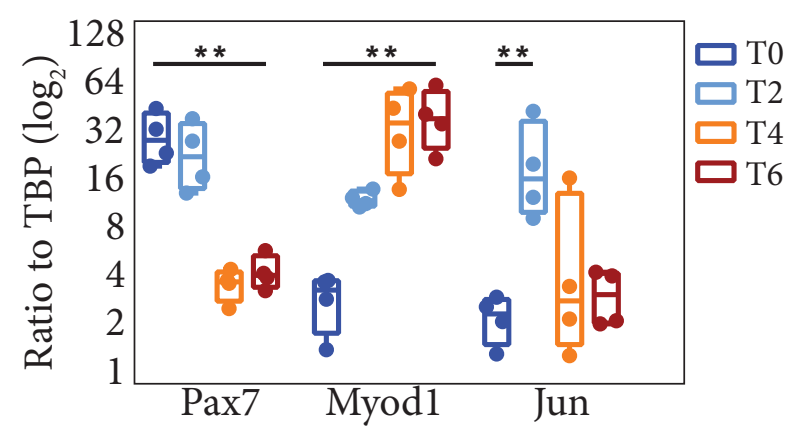

F

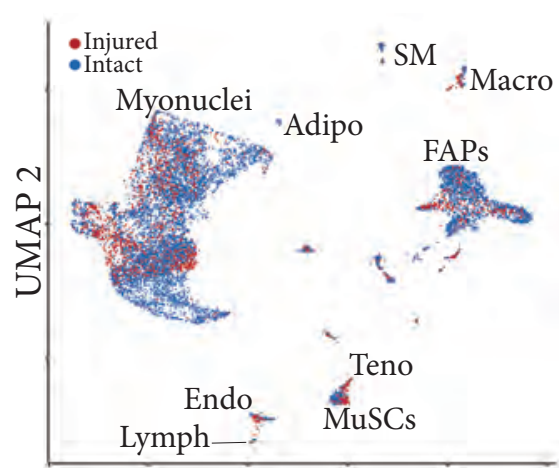

G

UMAP 1

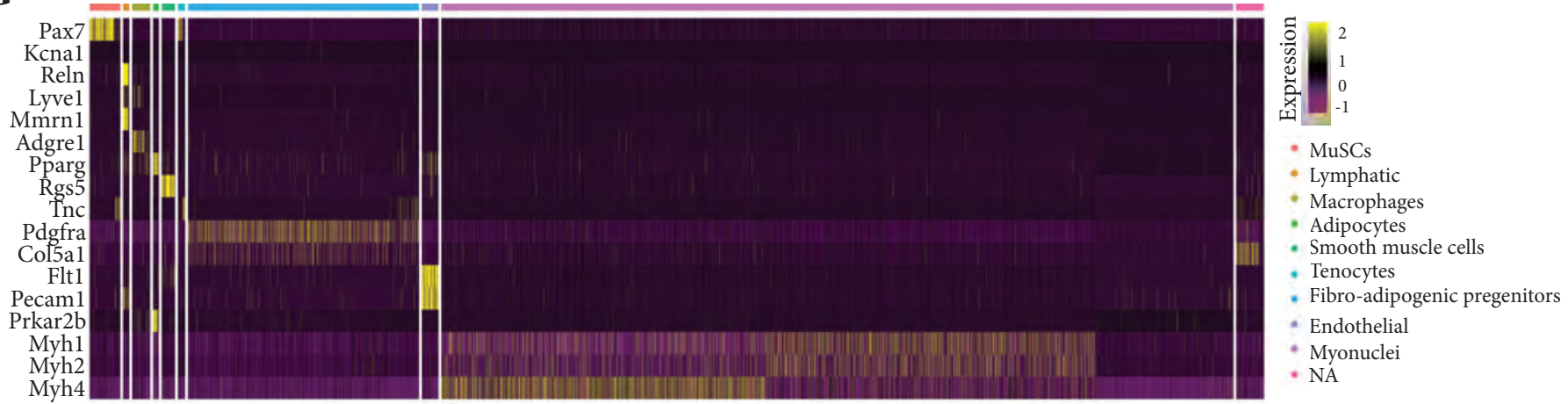


Figure S3. Stress response kinetics and quality controls related to single-nuclei RNA-seq experiments on intact and injured muscle and liver. Related to Figure 2.

(A) Measurement of early stress response to liver injury by RT-qPCR at $0,2,4$ and 6 h postinjection of $\mathrm{CCl}_{4}$. Transcripts were measured from bulk liver extracts. Statistical t-tests are T0/T2 for Fos, Jun, and Egrl and T0/T6 for Stat3, Il-6 and Igf-bp.

(B) UMAP plot of intact (blue) and injured (red) liver cells after data integration using Seurat3.

(C) Quality controls of intact and injured liver and muscle cells showing the number of UMI (left), the number of detected genes (middle), and the $\%$ of mitochondrial genes (right).

(D) Heatmap displaying the expression of common cellular populations markers used to annotate the nuclei from integrated intact and injured liver.

(E) Measurement of early MuSCs response to muscle injury $\left(1.2 \% \mathrm{BaCl}_{2}\right)$ by RT-qPCR at $0,2,4$ and $6 \mathrm{~h}$ post-injury. Transcripts were measured in FACS-isolated, $i S i F i$-treated MuSCs. Statistical t-tests are T0/T6 for Myodl and Pax7 and T0/T2 for Jun.

(F) UMAP plot of intact (blue) and injured (red) muscle cells after data integration using Seurat3.

(G) Heatmap displaying the expression of common cellular populations markers used to annotate the nuclei from integrated intact and injured muscle.

Independent student t-test was performed; ${ }^{*} \mathrm{p}<0.05, * * \mathrm{p}<0.01, * * * \mathrm{p}<0.001$. 
Figure S4 Machado et al., 2020

A

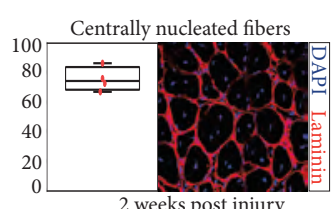

B

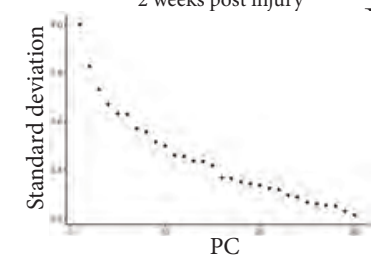

C

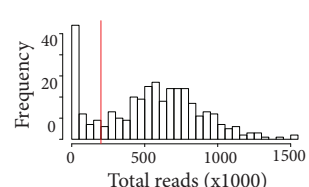

D

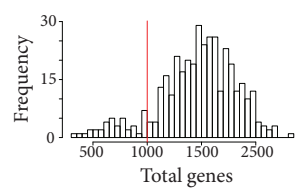

$\mathbf{E}$

F
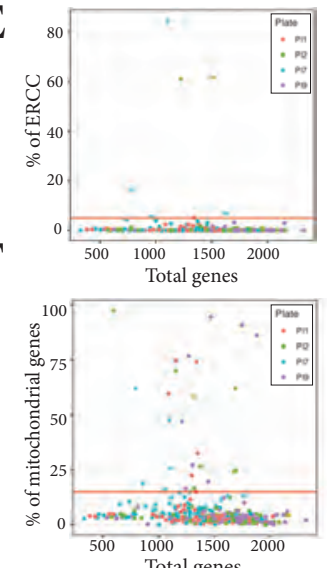

$\mathbf{G}$

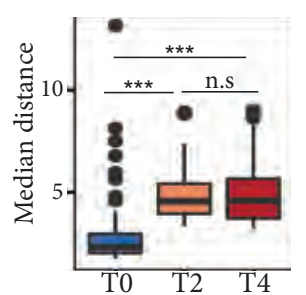

H

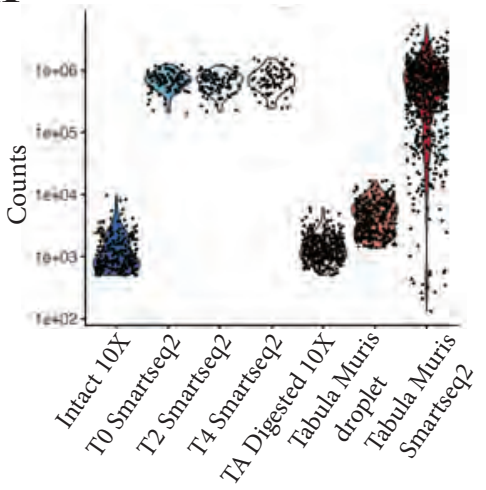

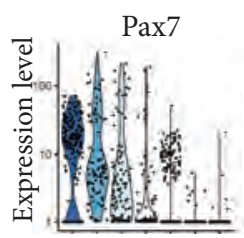

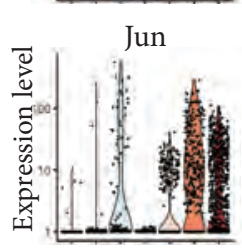

K

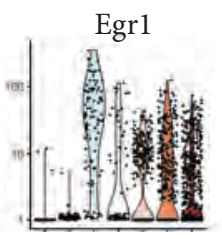

Fos

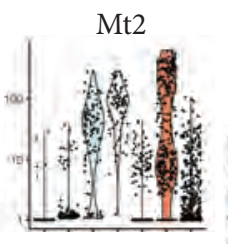

Fosb
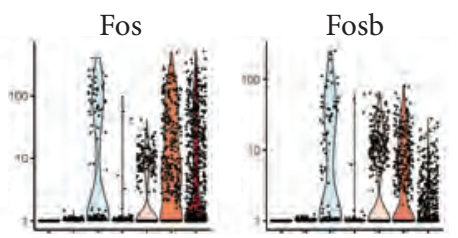

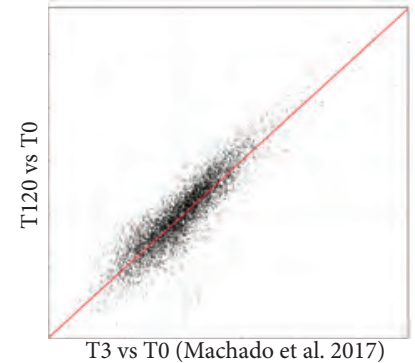

M

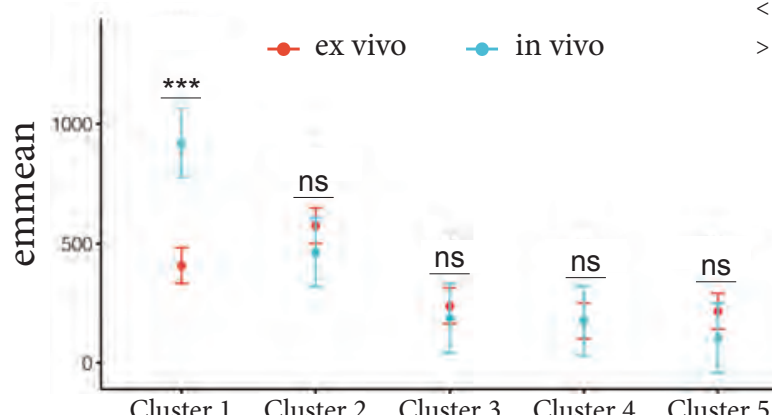

$\mathbf{N}$

$\begin{array}{lllll}\text { Cluster } 1 & \text { Cluster } 2 & \text { Cluster } 3 & \text { Cluster } 4 & \text { Cluster } 5\end{array}$

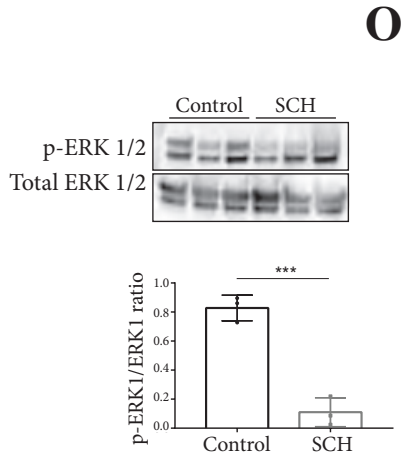

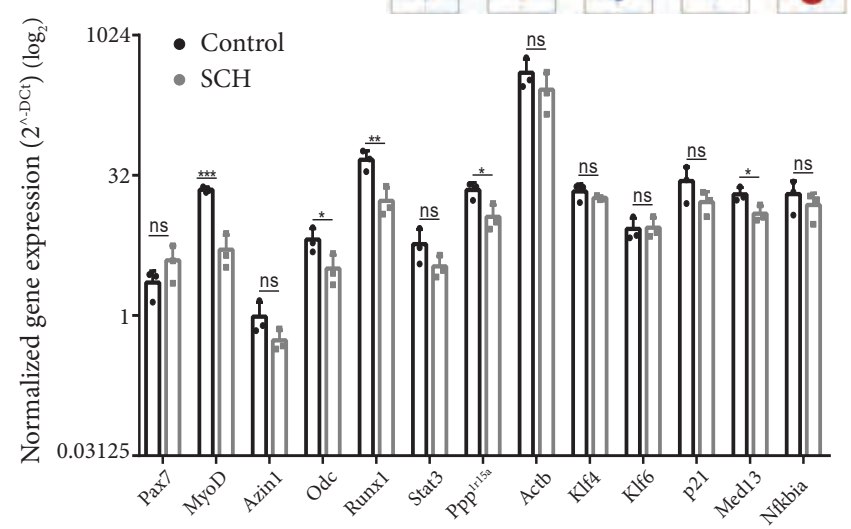

$\mathbf{L}$

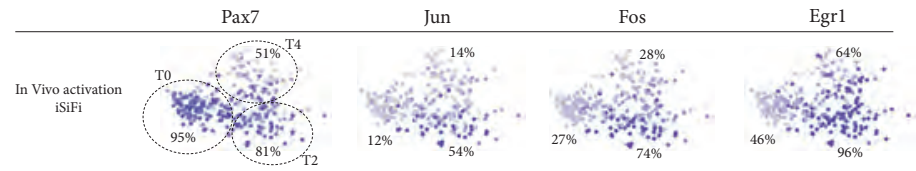

T4 Smartseq2
TA Digested 10X

Tabula Muris_droplet

Tabula Muris_Smartseq2

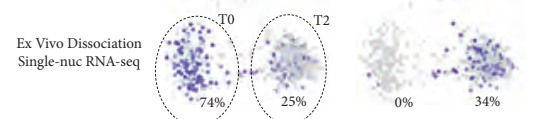

Tabula Muris

(3)

Wh

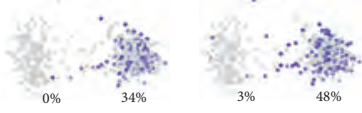

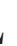

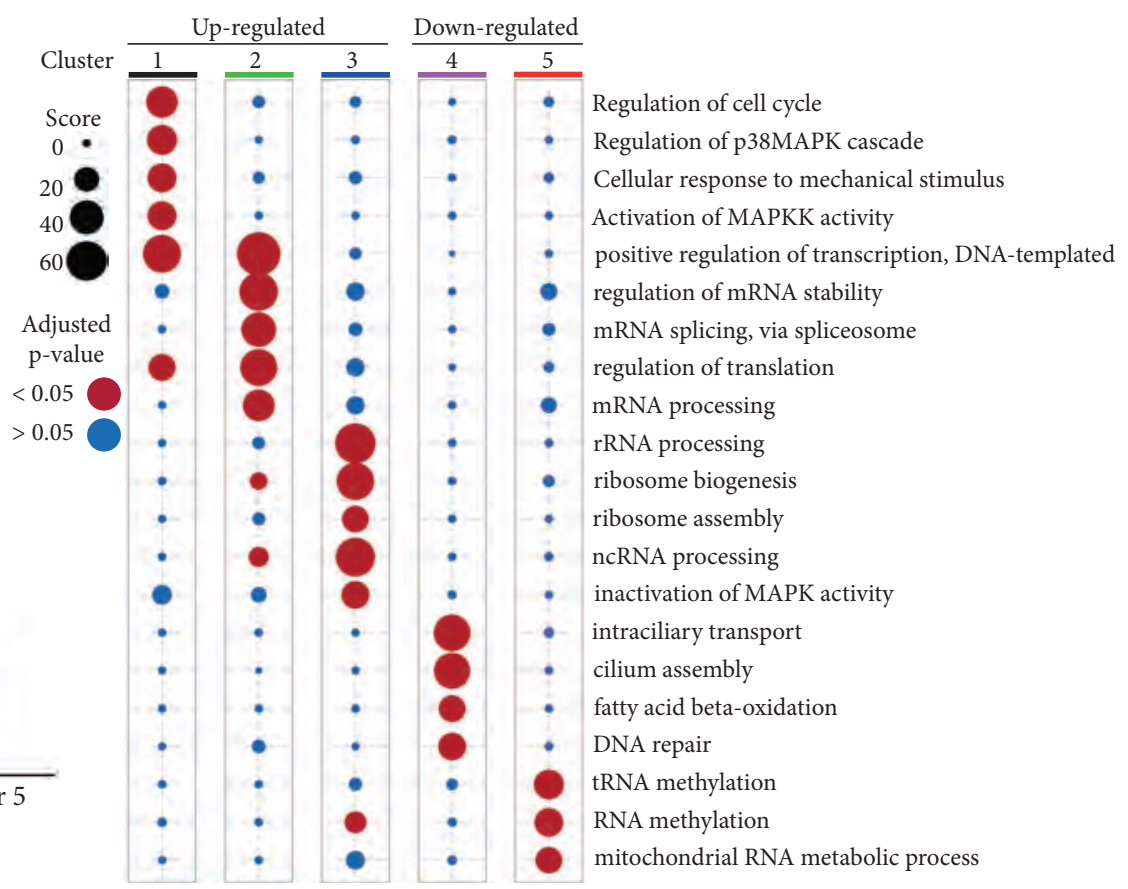

$\mathbf{P}$

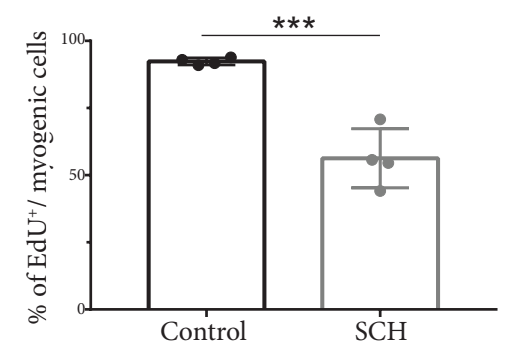


Figure S4. Muscle stem cells activation in vivo and in culture. Related to Figure 3 and Figure 4.

(A) Validation of the $\mathrm{BaCl}_{2}$ injury efficiency by staining for DAPI and laminin two weeks postinjury. Graph shows the percentage of centrally located nuclei in regenerated myofibers; $n=4$.

(B) Elbow plot showing standard deviations of first 30 principal components after standard lognormalization.

(C) Histogram displaying the distribution of reads per cell and the quality control cutoff (red line) set at 200 .

(D) Histogram displaying the distribution of detected genes per cell and the quality control cutoff (red line) set at 1000 .

(E) Dot plot representing the percentage of ERCC spikes-in contamination across all cells and the quality control cutoff (red line) set at 5\%.

(F) Dot plot representing the percentage of mitochondrial genes contamination across all cells and the quality control cutoff (red line) set at $15 \%$.

(G) Median Euclidian distance of each cell from the other cells within its group (time-point) as an indication of transcriptional heterogeneity $(\mathrm{T} 0=2.8, \mathrm{~T} 2=4.8$, and $\mathrm{T} 4=4.9)$. The first two principal components from Figure $2 \mathrm{~F}$ were used as coordinates.

(H) Number of UMIs in T0/T2/T4 MuSCs (single-cells, iSiFi, SmartSeq2), intact/dissociated MuSCs (single-nuclei, 10X genomics), and Tabula-Muris dissociated MuSCs (single-cells with SmartSeq2 and 10X Genomics droplets).

(I) Violin Plots showing the relative counts of specific stress-related genes between T0/T2/T4 injured MuSCs (single-cells, iSiFi, SmartSeq2), intact/dissociated MuSCs (single-nuclei, 10X genomics), and Tabula-Muris dissociated MuSCs (single-cells with SmartSeq2 and 10X Genomics droplets).

(J) Dynamic expression of selected genes from: (top line) T0, T2 and T4h iSiFi-treated singleMuSCs; (middle line) intact (T0) and dissociated (T2) MuSCs single-nuclei; (bottom line): freshly isolated MuSCs from the Tabula Muris Smart-Seq2 dataset. The dashed ellipses represent the approximate position of the different transcriptional clusters and the percentages the number of cells with at least 6 counts (iSiFi and Tabula Muris datasets) or 2 counts (single-nucleus dataset).

(K) Comparison of the T0/T120 fold changes (Fig. 3) and the T0/T3 (Machado et al., 2017) fold changes for shared genes, showing strong reproducibility between the two RNA-seq experiments. Note that T3 refers to MuSCs digested for $120 \mathrm{~min}$.

(L) Gene ontology analysis using EnrichR for all of the genes within each of the five clusters. Color code indicates p-value and circle size the combined enrichment score ( 0 to 60 ). The ontology terms that emerged during MuSCs dissociation represented a sequence of coherent biological processes: the triggering events (cluster 1) were initiation of transcription and stimulation of the 
MAPK cascade. This was followed by mRNA processing, including splicing and initiation of translation (cluster 2), and in a later phase by ontologies related to ribosome assembly and biosynthesis (cluster 3). Of note, late cluster 3 (maximum at T120) also contained ontologies related to inactivation of MAPK signaling, which coincides with the attenuation of the corresponding genes of early cluster 1 (drop at T120). The quiescence-to-activation transition is nevertheless characterized also by a downregulation of a significant number of genes. Indeed, we validated previous findings on T0-MuSCs enriched ontologies, including a switch from fatty-acid beta-oxidation to glycolysis, and processes related to cilium disassembly, (cluster 4). Of interest, cluster 5 was enriched in ontologies related to RNA methylation and mitochondrial RNA metabolic genes, yet the significance of these processes in quiescence-exit remains to be uncovered.

(M) Pairwise comparison between the gene clusters in ex vivo and in vivo activated MuSCs using an analysis of covariance test (ANCOVA).

(N) Western blot for total ERK1/2 and p-ERK1/2 from whole muscle extracts right after $2 \mathrm{~h}$ dissociation in the presence of DMSO (Control) or SCH772984. On the bottom, the ratio of intensity of p-ERK1 over total ERK1 is shown (upper bands).

(O) RT-qPCR on myogenic and stress core genes on freshly isolated MuSCs of Tg:Pax7-nGFP mice, from muscles dissociated in the presence or absence of $\mathrm{SCH} 772984$ ( $\mathrm{n}=3$ mice).

(P) Percentage of EdU ${ }^{+}$myogenic cells (Pax7 and/or Myog) in whole muscle bulk preparations cultured for $72 \mathrm{~h}$; EdU was added $24 \mathrm{~h}$ before fixation.

Independent student $\mathrm{t}$-test was performed. ns not statistically significant $* \mathrm{p}<0.05,{ }^{* *} \mathrm{p}<0.01$, $* * * p<0.001$. 
Supplementary Table S2. Summary of the digestion time of different tissues analyzed by the Tabula Muris consortium. Related to Figure 1.

\begin{tabular}{|c|c|c|}
\hline Tissue & Temperature & Digestion time (min) \\
\hline Heart & $37^{\circ} \mathrm{C}$ & 30 \\
\hline \multirow{2}{*}{ Aorta } & $37^{\circ} \mathrm{C}$ & 10 \\
\hline & $37^{\circ} \mathrm{C}$ & 30 incubation \\
\hline Lung & $37^{\circ} \mathrm{C}$ & 30 \\
\hline \multirow{2}{*}{ Trachea } & $4^{\circ} \mathrm{C}$ & $30-45$ \\
\hline & $37^{\circ} \mathrm{C}$ & $45-60$ \\
\hline Tongue & $37^{\circ} \mathrm{C}$ & 100 \\
\hline \multirow{2}{*}{ Liver } & $37^{\circ} \mathrm{C}$ & 15 \\
\hline & $4^{\circ} \mathrm{C}$ & 30 incubation \\
\hline Pancreas & $37^{\circ} \mathrm{C}$ & 40 \\
\hline \multirow{2}{*}{ Large intestine } & $37^{\circ} \mathrm{C}$ & 5 to 10 \\
\hline & $37^{\circ} \mathrm{C}$ & 60 incubation \\
\hline \multirow{2}{*}{ Kidney } & $37^{\circ} \mathrm{C}$ & 30 \\
\hline & $21^{\circ} \mathrm{C}$ & 5 \\
\hline Bladder & $37^{\circ} \mathrm{C}$ & 90 \\
\hline Limb muscle & $37^{\circ} \mathrm{C}$ & 90 \\
\hline Diaphragm & $37^{\circ} \mathrm{C}$ & 55 \\
\hline Skin & $37^{\circ} \mathrm{C}$ & 35 \\
\hline Mammary gland & $21^{\circ} \mathrm{C}$ & 120 \\
\hline Fat & $37^{\circ} \mathrm{C}$ & 30 \\
\hline \multirow{2}{*}{ Bone Marrow } & $4^{\circ} \mathrm{C}$ & Crushed \\
\hline & $4^{\circ} \mathrm{C}$ & 10 incubation \\
\hline Thymus & $37^{\circ} \mathrm{C}$ & 40 \\
\hline \multirow{2}{*}{ Spleen } & $21^{\circ} \mathrm{C}$ & minced \\
\hline & $21^{\circ} \mathrm{C}$ & 5 \\
\hline \multirow{2}{*}{ Brain, myoeloid cells } & $4^{\circ} \mathrm{C}$ & minced, dounced \\
\hline & $4^{\circ} \mathrm{C}$ & 10 \\
\hline \multirow{2}{*}{ Brain, non myoeloid cells } & $37^{\circ} \mathrm{C}$ & 10 \\
\hline & $37^{\circ} \mathrm{C}$ & incubation \\
\hline
\end{tabular}




\section{References in supplemental figures}

Contreras, O., Cruz-Soca, M., Theret, M., Soliman, H., Tung, L.W., Groppa, E., Rossi, F.M., and Brandan, E. (2019). Cross-talk between TGF- $\beta$ and PDGFR $\alpha$ signaling pathways regulates the fate of stromal fibro-adipogenic progenitors. J. Cell Sci.

Ishikawa, T., Factor, V.M., Marquardt, J.U., Raggi, C., Seo, D., Kitade, M., Conner, E.A., and Thorgeirsson, S.S. (2012). Hepatocyte growth factor/c-met signaling is required for stem cell-mediated liver regeneration in mice. Hepatology.

Van Meeteren, L.A., and Ten Dijke, P. (2012). Regulation of endothelial cell plasticity by TGF- $\beta$. Cell Tissue Res. 
Click here to access/download Supplemental Videos and Spreadsheets Supplementary Table 1.xlsx 
Click here to access/download Supplemental Videos and Spreadsheets Supplementary Table 3.xlsx 